\title{
Taxonomic revision of the stone geckos (Squamata: Diplodactylidae: Diplodactylus) of southern Australia
}

\author{
MARK N. HUTCHINSON ${ }^{1,3}$, PAUL DOUGHTY ${ }^{2} \&$ PAUL M. OLIVER $^{1}$ \\ ${ }^{\prime}$ South Australian Museum, North Terrace, Adelaide SA 5000, Australia, and School of Earth and Environmental Sciences, University \\ of Adelaide SA 5005, Australia. E-mail: hutchinson.mark@saugov.sa.gov.au \\ ${ }^{2}$ Department of Terrestrial Zoology, Western Australian Museum, 49 Kew Street, Welshpool, Western Australia 6106, Australia \\ ${ }^{3}$ Corresponding author
}

\begin{abstract}
The stone geckos of the Diplodactylus vittatus species-group are robust terrestrial geckos, mainly distributed through the southern half of Australia. Recent molecular analyses indicate that the current taxonomy significantly under-represents the true diversity in this group. Here we assess the morphological variation in the currently recognized species $D$. vittatus and $D$. granariensis, including the subspecies $D$. g. rex. We redescribe D. vittatus and D. granariensis, resurrect $D$. furcosus from the synonymy of $D$. vittatus and describe $D$. calcicolus $\mathbf{s p}$. nov. and $D$. wiru sp. nov. from semiarid habitats in western and southern Australia. Other than D. g. rex, most taxa are very similar for such characters as scalation, body and tail shape and size, but colour patterns show species-specific modal conditions, and the largely allopatric distributions mean that most areas support only one or two species which can be distinguished through a combination of characters. Further genetic data is required to resolve the systematic status and geographic distribution of additional deeply divergent genetic lineages in eastern Australia.
\end{abstract}

Key words: cryptic species, lizards, morphology, Squamata, systematics

\section{Introduction}

The Australian gecko fauna includes representatives of four families and over 160 recognised species (Han $e t$ al. 2004, Wilson \& Swan 2008). However a spate of relatively recent molecular studies have demostrated that cryptic speciation is widespread across many genera, and a significant number of species remain unrecognised (Pepper et al. 2006, Oliver et al. 2007, Oliver et al. 2009). Members of the gecko genus Diplodactylus Gray, 1832, are a striking case in point. In a recent genetic study Oliver et al. 2009, demonstrated that actual diversity within this genus was likely to be more than double the current recognized total of 14 . A significant proportion of this cryptic species diversity was concentrated within what appeared to be a basal grade of plesiomorphic species that were until the 1970s all referred to as Diplodactylus vittatus.

A karyotypic study by King (1977) initiated the breakup of what had been regarded as a single widelydistributed species, D. vittatus Gray, 1832 (Kluge 1967). This work revealed the existence of several regionally consistent groups based on either karyotype, colour pattern or both. King made no formal taxonomic changes, but Storr (1979) resurrected D. ornatus Gray, 1845, and D. polyophthalmus Günther, 1867, for two taxa along the west coast and southwestern forests of Western Australia. Storr (1979) also described the Western Australian populations remaining in D. vittatus as a new species, D. granariensis Storr, 1979, although this taxon included two chromosome races. Later, Storr (1988) described an additional subspecies, D. g. rex Storr, 1988, with large body size and distinctive colour pattern that occurred to the north of D. g. granariensis. The characters distinguishing the eastern $D$. vittatus and western $D$. granariensis were 
subtle (small differences in relative tail length, relative size of first and second labial scales), and Storr also suggested that some South Australian populations that were intermediate geographically and morphologically might represent a third species, for which the combination D. furcosus Peters, 1863, would be available (see also Bauer \& Henle 1994). Subsequent authors evidently found it difficult to use Storr's distinctions, and the standard reference for Australian reptiles (Cogger 1983) made an essentially arbitrary partition between $D$. vittatus (east of Port Augusta, South Australia) and D. granariensis (west of Port Augusta). In later editions Cogger recognized the subspecies D. g. rex but made no amendments to the 'Port Augusta line' that split $D$. granariensis and $D$. vittatus, and that unjustified decision has been followed ever since (e.g. Wilson \& Swan 2008).

A molecular genetic investigation by Oliver et al. (2007a) supported the existence of a western species that included King's $2 \mathrm{n}=36$ chromosome race and the type population of $D$. granariensis. It also supported the distinctiveness of King's $2 \mathrm{n}=34$ chromosome race, which includes populations from near the type locality of D. furcosus. In addition, it showed that there were at least four species level groups within the populations remaining in D. vittatus, including some populations in Storr's (1979) concept of D. g. granariensis. They also reported that specimens identified morphologically as $D$. g. rex were phylogenetically nested within more typical D. g. granariensis, providing no molecular genetic support for their recognition as a separate taxon. Oliver et al (2007b) later completed the sampling of Diplodactylus species, showing that the newly discovered lineages were distinct from Storr's other southwestern species, D. ornatus and D. polyophthalmus. Doughty et al. (2008) subsequently re-identified voucher specimens and found some morphological and molecular support (based on allozymes) for the distinctiveness of D. g. rex, and described the distinctive population of $D$. 'mitchelli' from the Northwest Cape of Western Australia as a new species, D. capensis Doughty et al., 2008.

In this paper we accept the findings from Oliver et al. (2007a) that there is prima facie evidence for a minimum of five and probably six species within the populations formerly referred to D. vittatus and $D$. granariensis. Molecular data are still deficient for eastern Australian populations but for the southern and western populations, genetic sampling has been sufficiently complete that all significant colour pattern and geographic groups have been assessed by DNA sequence data. The purpose of this paper is to present diagnostic data from external morphology that clarifies the limits of morphological variation of the two currently recognized species, $D$. granariensis and $D$. vittatus, investigates the status of the two subspecies of $D$. granariensis, and resurrects the long synonymized D. furcosus. In addition, we describe two new species from the southern coast and inland to establish a resolved taxonomy for the complex that better represents the patterns of evolutionary history and gene flow within this group.

\section{Materials and methods}

\section{Specimens examined}

In order to describe the genetic lineages found by Oliver et al. (2007a) as species, we concentrated our initial morphological studies on voucher specimens that had been the source of the genetic data. Having used these specimens in a pilot study we then expanded our sampling to increase the range of variation and geographic coverage.

\section{Morphology}

Specimens examined were mainly from the collections of the South Australian Museum, Adelaide and the Western Australian Museum, Perth, with additional material from the Australian Museum, Sydney, Queensland Museum, Brisbane, and Museum Victoria, Melbourne. For the descriptions and redescriptions, we included most of the adult specimens that had been genetically typed in the study by Oliver et al. (2007a). Data for the subspecies of D. granariensis are from Doughty et al. (2008). Specimens examined for morphological characteristics are listed in the Appendix. 
For the distribution map, we used the characters from our diagnoses to identify un-genotyped specimens in museum collections.

Abbreviations for regions and institutions: AMS, Australian Museum, Sydney; BMNH, Natural History Museum, London; NMV, Melbourne Museum; NSW, New South Wales; Qld, Queensland; QM, Queensland Museum, Brisbane; SA, South Australia; SAMA, South Australian Museum, Adelaide; Vic, Victoria; WA, Western Australia; WAM, Western Australian Museum, Perth; ZMB, Zoologische Museum der Universität Humboldt, Berlin.

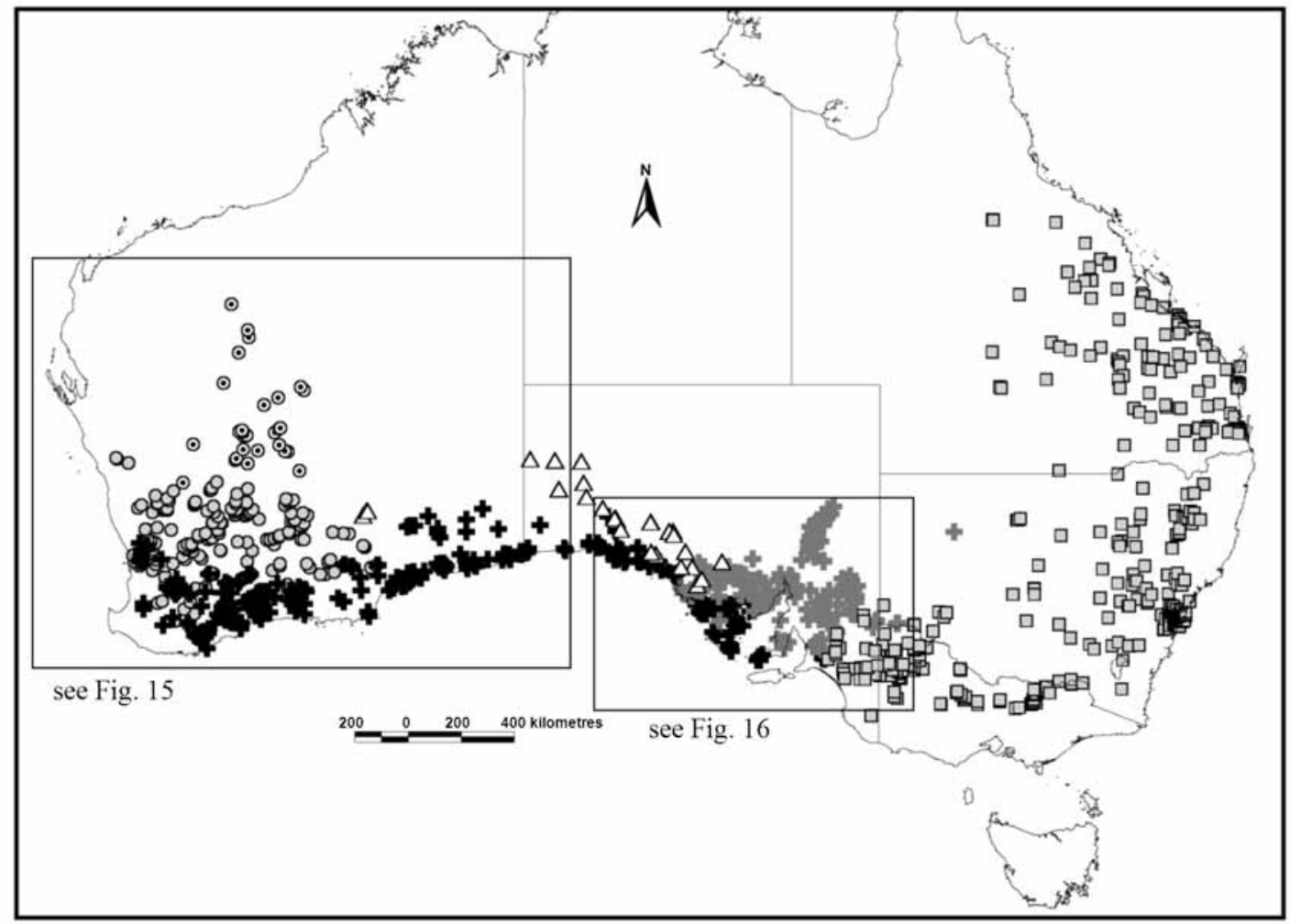

FIGURE 1. Map of southern Australia showing the distribution of the members of the Diplodactylus vittatus species complex described or re-described in the present study. Insets shows details of species distributions in overlap areas in Western Australia and South Australia (See Figs 15 and 16). Diplodactylus vittatus, square; $D$. furcosus, black cross, $D$. g. granariensis, circle; D. g. rex, circle with central dot, $D$. calcicolus sp. nov., grey cross, $D$. wiru sp. nov., triangle.

\section{Results}

For the most part we found that morphometric analyses provide few usable characters to aid in diagnosing the species. Females were larger than males, in snout-vent length (SVL) and trunk length, but there were no sex differences for other characters. There were differences in body size among taxa, with D. g. rex being much larger (max. SVL $72 \mathrm{~mm}$ ) than the other species, all of which had a maximum SVL of close to $60 \mathrm{~mm}$. Similar patterns existed for other characters, with D. g. rex larger in all measurements, and with few differences among the remaining taxa. When proportional differences were considered, there was little more to note. Tail length (used by Storr [1979]) as a percentage of SVL overlapped broadly across all species, although mean values showed some differentiation, with Diplodactylus vittatus tails averaging shortest (56.2\%) and $D$. furcosus longest (65.5\%). Another difference among taxa was the relative height of the first and second supralabial scales (a character used by Storr [1979] and Storr et al. [1990]). Diplodactylus vittatus and D. wiru sp. nov. consistently had the first supralabial taller than the second, in D. furcosus and D. calcicolus sp. nov. there was a weak tendency for the first labial to be taller than the second, while in D. granariensis (both 
subspecies) the two scales were subequal. This character has value in distinguishing species in which it is consistent, but it is not as reliable as first implied by Storr.

Despite the lack of scalation and mensural differences among the taxa other than for D. g. rex, there were consistent differences in dorsal colour patterns that were useful in diagnosing taxa. Dorsal colour patterns could be broken down into a series of coordinated pattern elements, namely the degree of continuity of the pale vertebral stripe, the degree to which this stripe has a discrete dark border, the presence, number and relative size of pale spotting on the flanks, whether these spots have contrasting margins of darker colour, and the occipital pattern, varying from a uniform pale cap to a bifurcate pattern with a pale stripe to the back of each eye defining a triangular occipital patch. We found that most individuals of all species conformed to just one or a few combinations from this set of potential variants. As a result, we find that we can provide a set of colour pattern guidelines that, together with restrictions imposed by geographic distributions, should enable accurate identification of the great majority of specimens from pattern alone. On the other hand, in the absence of locality data, specimens of the different species can show sufficient overlap in all features that confident identification of some individuals may be very difficult.

\section{Taxonomy}

\section{Reptilia}

\section{Squamata}

\section{Diplodactylidae Underwood, 1954}

\section{Diplodactylus Gray, 1832}

Type species: D. vittatus Gray, 1832, by monotypy.

Diagnosis. A genus of the Diplodactylidae (Han et al. 2004) distinguished from all but Lucasium and Rhynchoedura by having both lateral and medial pairs of cloacal bones present. Distinguished from Lucasium and Rhynchoedura by the anteriorly enlarged jugal bone that enters the floor of the lacrimal foramen, by having relatively high numbers of preanal spinose scales (generally $>5$ ), absence of preanal pores and shorter, stouter proportions of the body and tail; fourth toe on hind foot approximately four times as long as wide, tail generally swollen and less than $80 \%$ of SVL (Oliver et al. 2007b).

The D. vittatus species complex. Oliver et al. (2007a) referred to lizards described below as the $D$. vittatus species complex, and the data presented there and in Oliver et al. (2007b) show that they form a paraphyletic assemblage within Diplodactylus. They share a general similarity in habitus and colour pattern, sufficiently similar that all were formerly combined as a single species, D. vittatus, sensu Kluge (1967).

The head and body are moderately stout in general proportions, limbs are of moderate length and build, the tail shows little taper until near the tip and frequently has its maximum diameter at about the midpoint, producing a spindle-shape. The undersides of the digits typically have a single series of enlarged, hemispherical subdigital 'lamellae' which tend to break up into smaller scales towards the base of the toes. The labial scales are differentiated from adjacent scales and the nostril is generally surrounded by the rostral, two supranasals, two or three small postnasals, and the first supralabial. There are no tubercular or spinose caudal scales.

The species are coloured in shades of grey, brown or reddish-brown and black, with a dorsal pattern that includes a pale vertebral stripe usually scalloped to produce a zigzag shape, but which may be straight-edged, or broken into a series of angular or irregular dorsal blotches. The vertebral stripe may fork on the neck with a process extending to each eye, or may broaden to form a pale cap over the nape and dorsal surface of the occipital and parietal areas. The edges of the vertebral stripe are weakly to boldly edged with blackish paravertebral margins, the colour fading laterally to a medium shade of grey or brown. The light dorsal stripe 
continues on to the tail when original, but is often less continuous on the tail than on the body. Colouring of the flanks can be divided into an upper lateral zone of a medium to dark shade of the basic body colouring, and a lower lateral zone that is an extension of the ventral colouring. The upper lateral zone may be immaculate, with or without a peppering of paler and darker scales, or may have a few to many small to large circular spots. Limbs are coloured and patterned similarly to the body. The venter is unmarked light grey to white.

The only member of the complex to depart from this general scheme is D. polyophthalmus, which has an indistinct pale vertebral zone and numerous small, blurry pale dorsal spots. The tendency of all of the markings of $D$. polyophthalmus to 'bleed' into the surrounding colour distinguishes it from all other members of the complex.

The similar species section is based on areas of sympatry and parapatry, and is designed to draw attention to distinguishing features of species that might be found together. As most species show extensive overlap in morphology, this focuses attention on to those characters that are most useful for particular combinations of species.

\section{Diplodactylus vittatus Gray, 1832}

Eastern Stone Gecko

Figs. 2, 3, 14A

Diplodactylus vittatus Gray, 1832: 40. Holotype BMNH 1946.9.7.43 from Australia ('Nova Hollandia') (Fig. 2). Probable type locality the western slopes of the Great Dividing Range, NSW (see Storr [1979] and below).

Diplodactylus 'eastern coastal' Oliver et al., 2007a

Diplodactylus 'eastern inland' Oliver et al., 2007a

Diagnosis. A relatively short-tailed member of the $D$. vittatus complex, with a relatively narrow, zigzag to straight-edged dorsal stripe extending on to the head as a pale cap with a weak darker central triangle. Spotting on flanks absent to moderate; when present, spots are small and without darkly pigmented margins.

Description (Figs 3, 14A). SVL 37.0-59.5 mm (mean 50.6, n=33); tailL 21.0-33.0 mm mean 28.6 (48.9-63.5\% SVL, mean 56.2) $(\mathrm{n}=14)$. Supralabials $10-14$ (mean 12.1, $\mathrm{n}=19)$, the first slightly to distinctly taller than the second. Infralabials 10-14 (mean 11.4, n=19). Apex of rostral scale with median division descending to about the mid-height of the scale. Supranasals usually in contact; a single internarial present in 5 of 33 examined. $3-5$ postnasals (mean $3.7 n=33$ ).

Dorsal colour medium to dark grey or grey-brown. Beige to light grey vertebral stripe most often continuous, relatively narrow and with a strongly scalloped margin; less often broken into a chain of angular vertebral blotches or continuous and straight-edged. Vertebral stripe varies where it terminates on the head, usually expanding to form a pale cap, but sometimes with a weak bifurcation due to an inverted triangle of somewhat darker colouring that may contrast with the more lateral pale colour. Blackish paravertebral margins of vertebral stripe continuous but variable in contrast, from bold and wide to narrow and weakly contrasting with the lateral colouring. Upper lateral zone sometimes irregularly patterned with small, circular spots that lack distinct darker edges. Apart from the above, the upper lateral surfaces have a faintly textured colour pattern made up of a medium to dark background colour with a scattering of weakly contrasting darker and lighter scales. Venter white to greyish-white.

Karyotype. $2 \mathrm{n}=38$, all acrocentric (King 1977).

Distribution. The southeastern inland of Australia from around Murray Bridge in SA, east into Victoria and running north along the inland slopes of the Great Dividing Range through NSW to central eastern Queensland (Figs 1, 16).

Habitat. Found in a variety of semiarid to dry temperate habitats, from sandy mallee in the south to rocky hill slopes in tall open forest in the Great Dividing range. 
Similar species. The distribution of $D$. vittatus abuts or narrowly overlaps those of $D$. furcosus and $D$. calcicolus sp. nov. Specimens of $D$. vittatus can be distinguished from sympatric and parapatric specimens of these species as follows: from both by the relatively shorter tail (usually less than 60\% SVL, versus usually greater), from $D$. furcosus by the darker grey-brown body colour, light dorsal stripe outlined by thick black outlines that bleed into the lighter background colour, and lacking obvious bifurcation of the dorsal stripe on the occipital region (although the occiput generally has a darker $\mathrm{V}$ of the gound colour); from D. calcicolus sp. nov. by continuous narrow dorsal stripe not broken into irregular blotches, and lack of complex lateral pattern of intermixed dark and light scales.

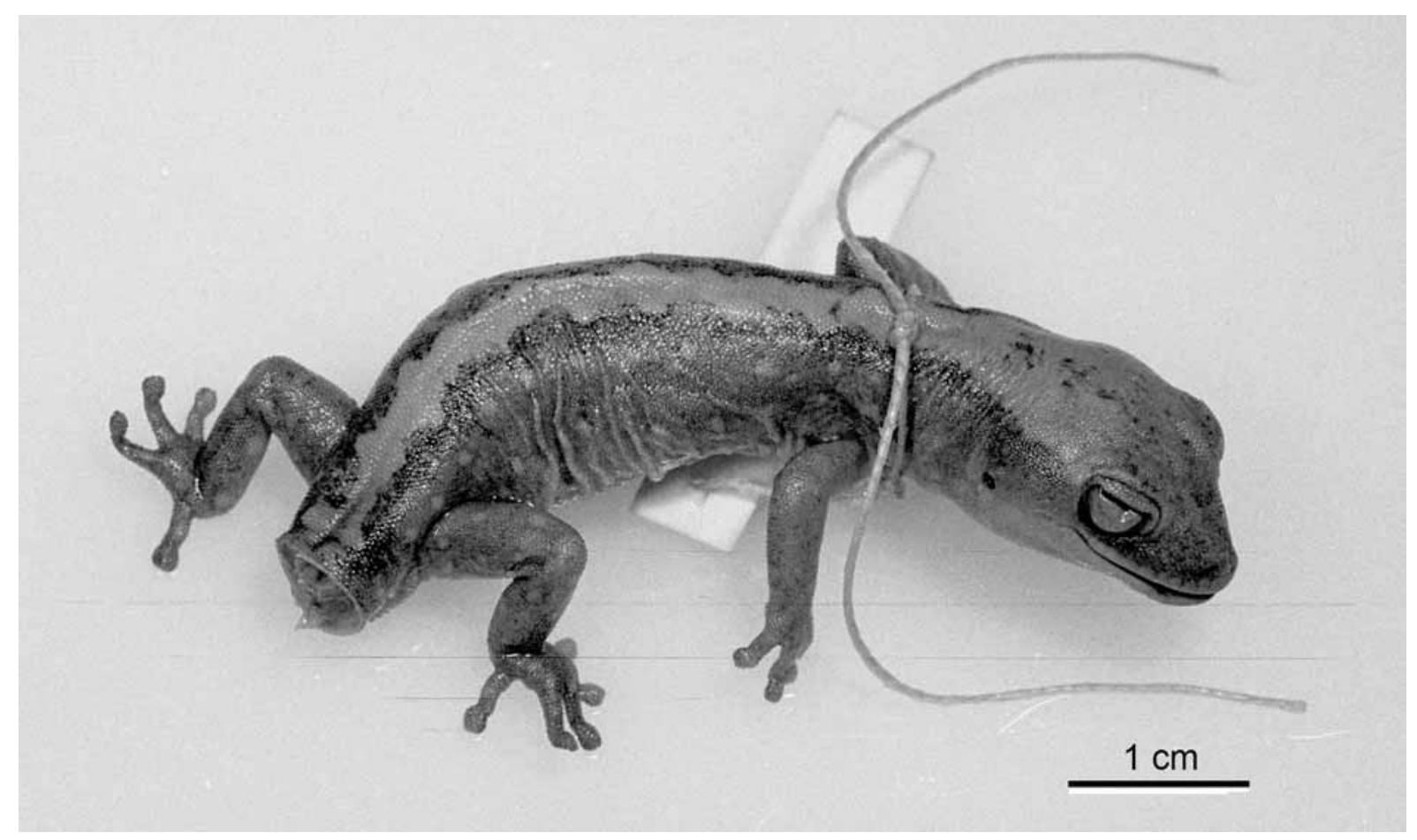

FIGURE 2. Holotype of Diplodactylus vittatus, BMNH 1946.9.7.43. Photo: H. G. Cogger.

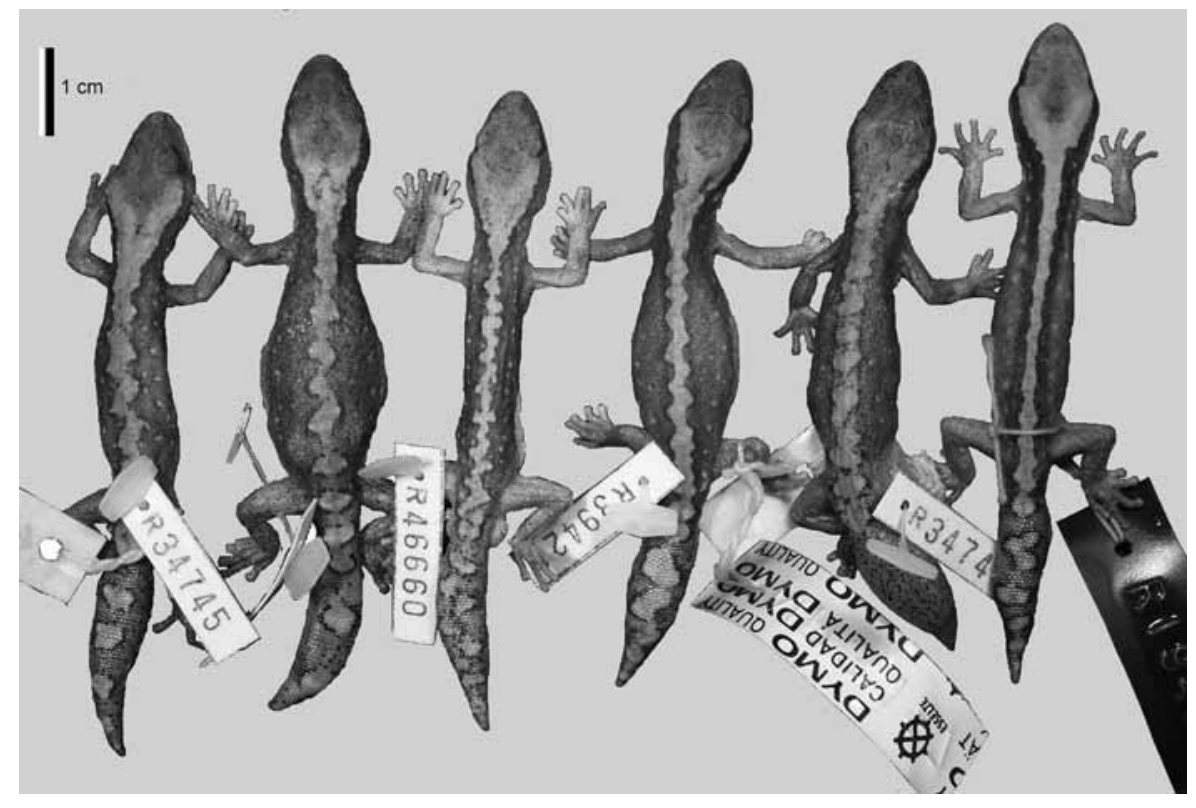

FIGURE 3. Variation in colour pattern in Diplodactylus vittatus. 
Other members of the $D$. vittatus complex can resemble $D$. vittatus, the most similar being $D$. granariensis, $D$. ornatus and $D$. wiru sp. nov., which are very similar in colour and pattern to some $D$. vittatus. When compared in detail, $D$. vittatus can generally be distinguished from these taxa by a combination of a shorter tail (usually less than $60 \%$; Table 2) and consistent presence of the first supralabial taller than the second. In addition, D. granariensis and D. ornatus have a triangular zone of dark background colour on top of the head, $D$. wiru sp. nov. has consistent presence of lateral spots with obvious black margins and $D$. ornatus has numerous large and irregular pale lateral spots.

Remarks. Kluge (1969) interpreted the likely source of the type specimen of $D$. vittatus as somewhere on the west coast of Australia, most probably from the Perth area, based on the collector (Alan Cunningham) having visited the area on surveying expeditions between 1817 and 1822. However there is a long gap between this period of time and the description of the species by Gray (1832). Much closer in time to the description, between 1827 and 1829, Alan Cunningham, led a series of surveying trips along the western slope of the Great Dividing Range between Bathurst and the Darling Downs in southeast Queensland (McMinn 1970). He returned to England shortly afterwards and appears to have brought with him the specimens described by Gray. One of the species described at the same time as D. vittatus, Egernia cunninghami Gray, 1832 was from a locality in eastern Australia 'in latitude $29^{\circ} \mathrm{S}$ '. It seems reasonable to infer that the type of $D$. vittatus was also collected from this general region (the western slopes of the Great Dividing Range in northern NSW), where both $E$. cunninghami and $D$. vittatus are relatively common and widespread. The appearance of the type specimen is consistent in appearance to specimens from the western slopes of NSW, including a relatively tall first supralabial (markedly taller than second). We therefore concur with Storr (1979) in finding no justification for Kluge's attempt to restrict the type locality to the Darling Range in Western Australia.

Phyllodactylus barbouri Angel 1936 (type locality Madagascar, in error) has been regarded by previous authors (Kluge, 1969; Cogger et al. 1983) as a junior synonym of D. vittatus (sensu lato). Brygoo (1991) reported that, in his opinion, the type and only specimen was indistinguishable from $D$. granariensis. Bauer \& Henle (1994) noted that as the taxonomy stood at that time, Brygoo's conclusion would have to include the possibility that barbouri might be a junior synonym of furcosus rather than granariensis. As we have now restricted the concept of $D$. granariensis, and have not examined the holotype, future work on the $D$. vittatus species complex will need to determine whether the holotype can be assigned to any of the taxa recognized here.

Across its distribution, D. vittatus shows considerable colour pattern variation. Our study has not made a detailed investigation of this variation as we have not had the tissue samples that would have allowed us to assess their significance (see further comments in discussion). Some variation may show geographic trends, such as a greater frequency of specimens from Qld that have relatively wide, straight-edged dorsal stripe, or coastal NSW specimens with more broken dorsal stripes and greater frequency of lateral spotting.

\section{Diplodactylus furcosus Peters, 1863}

Ranges Stone Gecko

Figs. 4, 5, 14B

Diplodactylus furcosus Peters, 1863: 229. Lectotype ZMB 39231 from Buchsfelde (southwestern outskirts of Gawler), SA (Fig. 4).

Diagnosis. A moderate-sized, longer tailed member of the $D$. vittatus complex, with strongly scalloped to zigzag vertebral stripe, sometimes a chain of angular blotches, strongly bifurcating on the head and extending as a relatively narrow dark-edged pale stripe to each eye. Flanks with no, small or large pale circular lateral spots. Pale markings thinly outlined in black. 


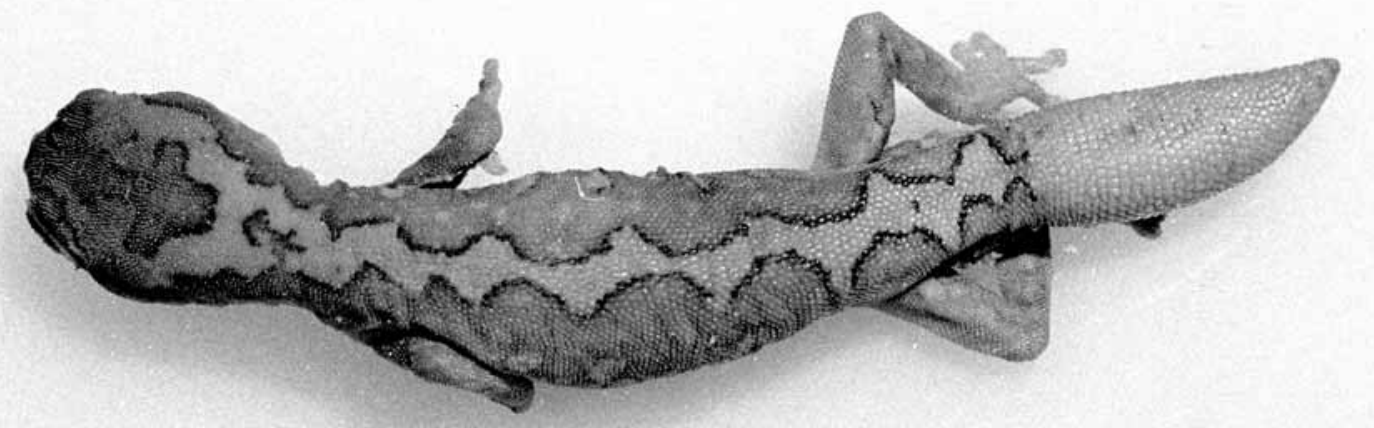

$1 \mathrm{~cm}$

FIGURE 4. Lectotype of Diplodactylus furcosus, ZMB 39231. Photo: H. G. Cogger.

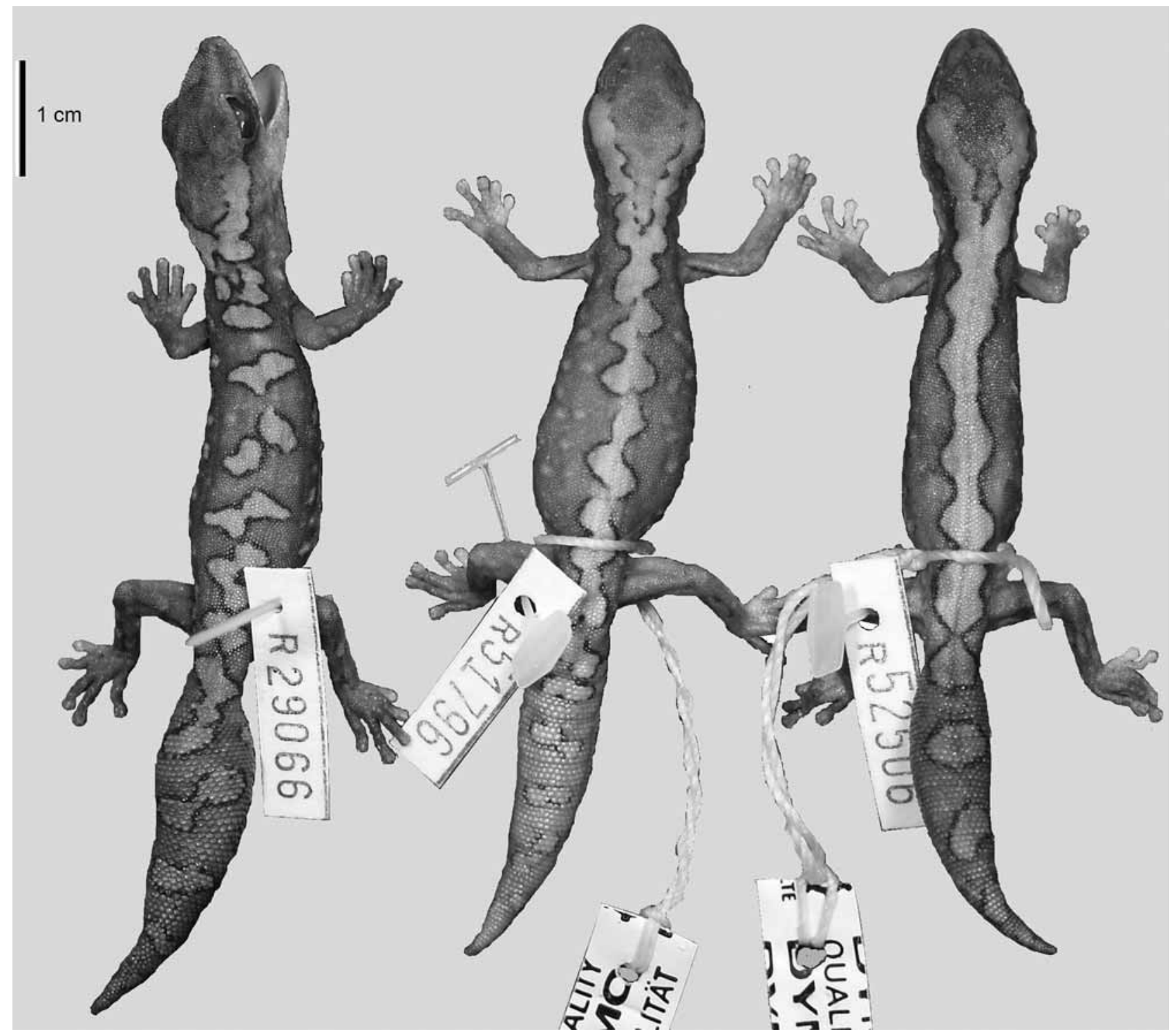

FIGURE 5. Variation in colour pattern in Diplodactylus furcosus.

Description (Figs. 5, 14B). SVL 37.0-58.0 mm (mean 50.7, $\mathrm{n}=30$ ); tailL 22.0-26.0 mm, mean 32.0 (55.2-68.6\% SVL, mean 65.5) $(\mathrm{n}=21)$. Supralabials 9-13 (mean 11.3, $\mathrm{n}=22)$, the first usually distinctly taller than the second. Infralabials 9-13 (mean 10.5, $\mathrm{n}=22$ ). Apex of rostral scale with median division descending 
to about the mid-height of the scale. Supranasals usually in contact; a single internarial present in 5 of 30 examined. $2-4$ postnasals (mean $3.3, n=30$ ).

Dorsal colour medium brown, grey-brown or tan. Beige vertebral stripe with strongly scalloped to zigzagged margins, sometimes broken into a chain of angular pale blotches. Vertebral stripe bifurcates on the nape forming a pair of pale stripes, margined with black, terminating at the eye, and leaving an inverted triangular patch of the dorsal colour on the crown and occiput of the head. Blackish paravertebral margins of vertebral stripe prominent but narrow (one to two scales wide) and contrasting sharply with both the light vertebral colour and the medium shade of the upper lateral zone. Upper lateral zone usually well marked with one or more irregular series of small to moderate, well-defined, and sometimes dark-edged circular spots. As with the paravertebral markings, any dark margins of the spots tend to contrast sharply with the adjacent colour. The background colour of the upper lateral zone is uniform, without a peppering of lighter or darker scales. Venter immaculate off-white.

Karyotype. $2 n=34$, with two large metacentric pairs, the presumed fusion products of chromosomes $3+5$ and 4+6 from the $2 n=38$ karyotype; remainder acrocentric (King 1977).

Distribution. Southern interior of SA, from the western margin of the Gawler Ranges around Minnipa and Wirrulla, through the Gawler and Middleback Ranges to the Flinders and Mount Lofty Ranges, extending east to the Murray River, and along the northern margin of the Murray into the far west of NSW (Figs 1, 16).

Similar species. The distribution of $D$. furcosus abuts or overlaps those of $D$. vittatus, D. calcicolus $\mathbf{s p \text { . }}$ nov. and $D$. wiru sp. nov. Specimens of $D$. furcosus can be distinguished from sympatric and parapatric specimens of these species as follows: from $D$. vittatus by the bifurcate head marking and lighter brown colour with the pale markings outlined by narrow but highly contrasting black lines, and longer tail; from $D$. calcicolus sp. nov. by lack of complex lateral pattern of intermixed dark and light scales and generally a more continuous and boldly outlined dorsal pale stripe. Some specimens of D. calcicolus sp. nov. have continuous dorsal stripes that bifurcate on the head, but these can be distinguished from $D$. furcosus by having intermixed light and dark scales peppering the flanks, and frequently have a prominent row of very large spots along the flanks where the dorsal colour merges with the ventral colour. Diplodactylus furcosus can be distinguished from $D$. wiru sp. nov. by the strongly bifurcate occipital marking, rather than pale cap, and narrow, sharply outlined pale dorsal markings, rather than having thick dark outlines that may merge with the dorsal background colour.

Occasional specimens of some other members of the $D$. vittatus complex can resemble $D$. furcosus, but the light colouring and sharp narrow black outlines of the dorsal markings usually distinguish $D$. furcosus. Further distinguished from $D$. granariensis and D. ornatus by the narrow bifurcation of the stripe towards each eye which has more well-defined inner margins.

Remarks. The holotype of Diplodactylus furcosus (ZMB 39231) clearly preserves the distinctive colour pattern of pale zigzag dorsal stripe narrowly but prominently margined in black and bifurcating on the nape to form well-defined, relatively narrow stripes to each eye. All specimens of the D. vittatus complex occurring within a $60 \mathrm{~km}$ radius of the type locality are readily assignable to $D$. furcosus.

In life most specimens of this species have a light tan background colour, distinctly different in hue to the more grey to greyish-brown dorsal colour of the other southern and eastern members of the complex. In most parts of its range this species is associated with rocky areas or bare stony soils, and there are few records from habitats where the soil is sandy.

\section{Diplodactylus granariensis Storr, 1979}

Diagnosis. The species $D$. granariensis is distinguished from other stone geckos by a combination of strongly-developed, wavy-edged to almost straight dorsal stripe, extending on to the head as a very broad bifurcate pale stripe to each eye and flanks with no, or only small, and poorly-defined pale spots and the second supralabial consistently as tall as or taller than the first. 
Diplodactylus granariensis granariensis Storr, 1979

Western Stone Gecko

Figs. 6, 7, 14C.

Diplodactylus granariensis, Storr 1979: 397. Holotype WAM R54239 from Walyahmoning Rock, WA.

Diagnosis. A moderate-sized member of the D. vittatus complex, with strongly-developed, wavy-edged to almost straight dorsal stripe, extending on to the head as a very broad bifurcate pale stripe to each eye. Flanks unmarked or with only small and poorly defined pale spots.

Description (figs 6, 7 14C). SVL 44.0-62.0 mm (mean 54.3, $\mathrm{n}=32$ ); tailL 22.0-39.0 mm, mean 33.0, (48.6-71.2 \%SVL, mean 62.3) $(\mathrm{n}=29)$. Supralabials 10-15 (mean 11.9, $\mathrm{n}=32)$, relative height of first and second supralabial generally subequal or the second slightly higher than the first. Infralabials 10-15 (mean $11.9, \mathrm{n}=32$ ). Apex of rostral scale with median division descending to about the mid-height of the scale. Supranasals usually in contact; a single internarial present in 4 of 32 examined. 2-3 postnasals (mean 3.1, $\mathrm{n}=32$ ).

Dorsal colour medium to dark brown, greyish-brown or tan. Beige vertebral stripe continuous, with margins that are almost straight, or no more than moderately scalloped. Vertebral stripe bifurcates on the nape to form two very wide stripes ending at the eyes. Inner margins of these stripes define a relatively small inverted triangle of the dorsal body colour confined to the parietal region. Blackish paravertebral margins of vertebral stripe strongly developed, tending to merge gradually with the colouring of the upper lateral zone, but sometimes forming a broad blackish dorsolateral stripe, well demarcated from both the vertebral and lateral colours. Upper lateral zone usually immaculate and uniformly coloured, without a peppering of lighter or darker scales. At most, lateral patterning consists only of scattered small lighter spots that lack obvious dark margins.

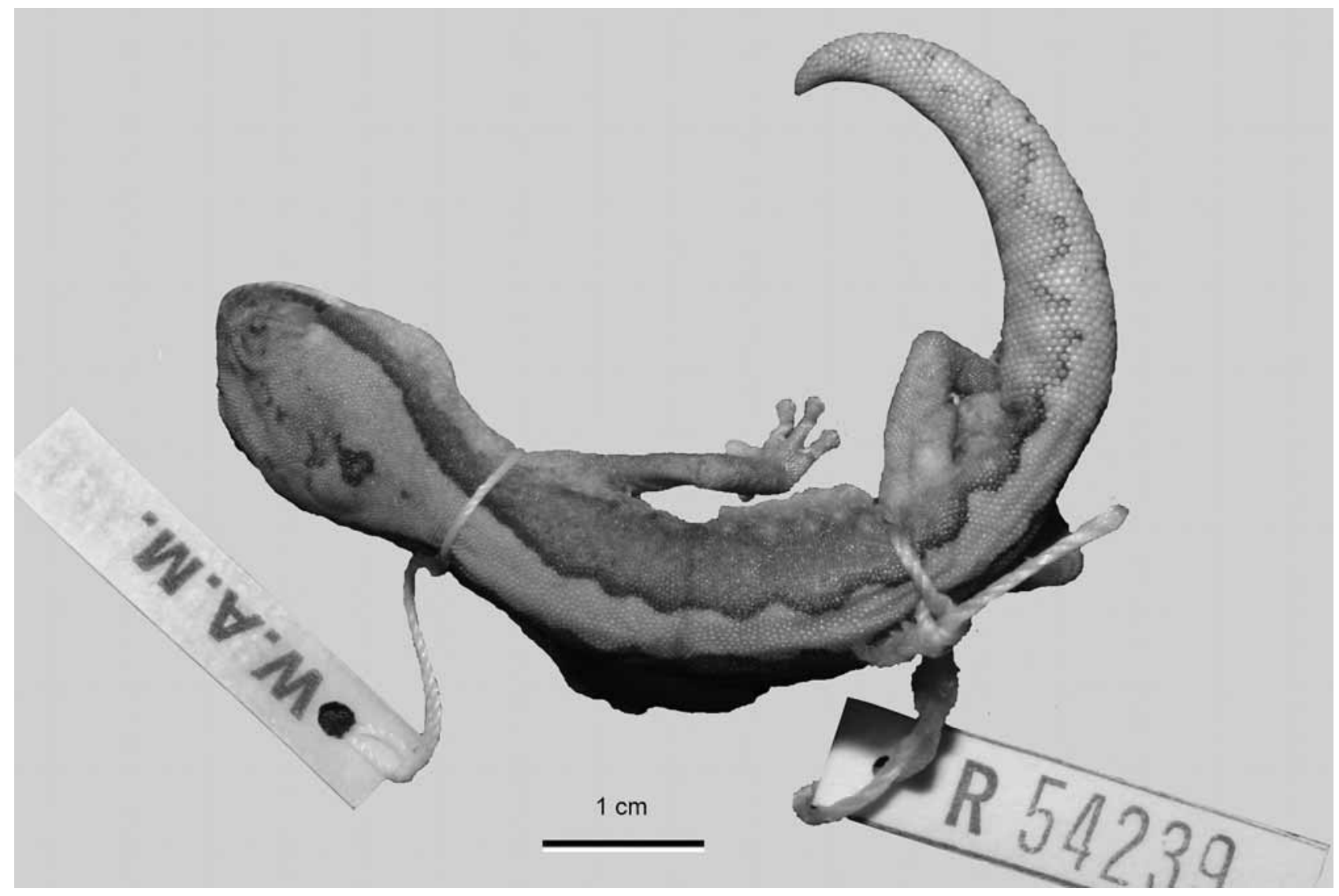

FIGURE 6. Holotype of Diplodactylus granariensis, WAM R54239. 


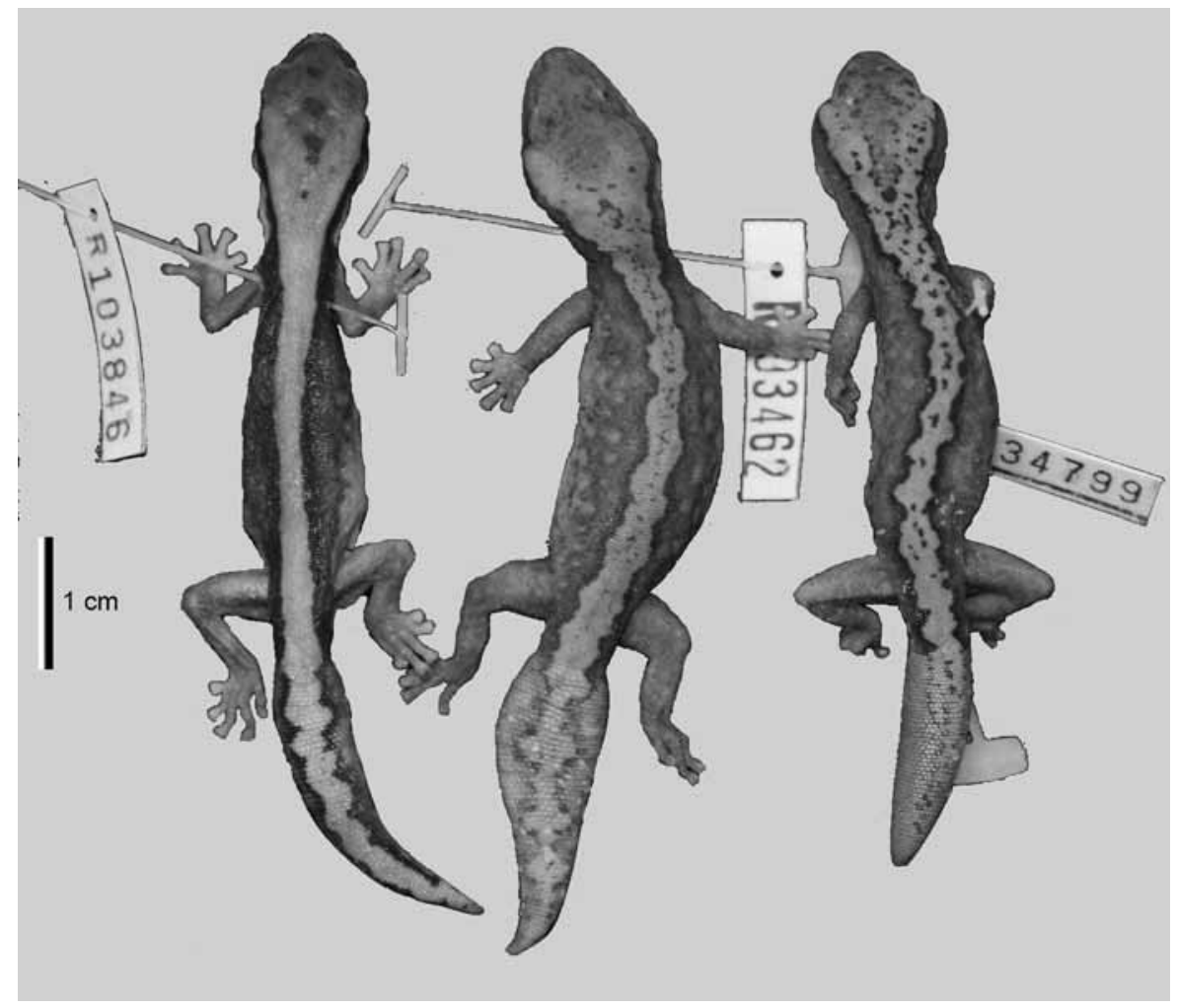

FIGURE 7. Variation in colour pattern in Diplodactylus granariensis granariensis.

Karyotype. $2 n=36$; a submetacentric pair 1 is the presumed fusion product of pairs $1+3$ of the $2 n=38$ all acrocentric karyotype. All other chromosomes acrocentric (King 1977).

Distribution. Southwestern interior of Western Australia, east to Zanthus, but absent from the coastal plain and high rainfall southwestern forests and coasts (Figs. 1, 15).

Similar species. Distinguished from D. g. rex by lack of a dark upper lateral stripe, presence of a rostral crease and smaller size. Distinguished from sympatric and parapatric species as follows: from D. ornatus and D. calcicolus sp. nov. by lack of complex lateral pattern of intermixed dark and light scales and more continuous and straighter-edged dorsal pale stripe; from $D$. wiru sp. nov. by bifurcate occipital marking, rather than pale cap, and absent or weak pale lateral spots which, when present, lack dark borders.

Remarks. When Storr (1979) described D. granariensis as distinct from D. vittatus in the east, he did not make use of the chromosome data of King (1977) who showed that there were different chromosomal races of 'D. vittatus' across southern Australia. Perhaps owing to the wide overlap of distributions of D. granariensis s.s. and D. calcicolus sp. nov., and the similarity in scalation and (sometimes) dorsal pattern, he conservatively pooled both taxa for his description of $D$. g. granariensis. However, the type population of $D$. granariensis, morphologically indistinguishable from nearby animals known to have a $2 \mathrm{n}=36$ karyotype (King 1977), is strongly genetically divergent (Oliver et al. 2007a) from more southerly populations that include animals with a $2 n=38$ karyotype. Our study shows that the two genetic and karyotypically distinct groups are also distinct morphologically, and the southern populations that have much more broken and spotted colour patterns are described below as a new species.

\section{Diplodactylus granariensis rex Storr, 1988}

Giant Stone Gecko

Figs 8, 9, 14D

Diplodactylus granariensis rex Storr, 1988: 220. Holotype WAM R97288, 44 km southeast of Leinster, WA. 
Diagnosis. A large-bodied, shorter-tailed member of the D. vittatus complex, usually lacking a rostral crease. Colour pattern includes a strongly-developed, wavy-edged to almost straight dorsal stripe, extending on to the head as a very broad bifurcate pale stripe to each eye. Upper flanks lighter and bordered below by a dark midlateral stripe.

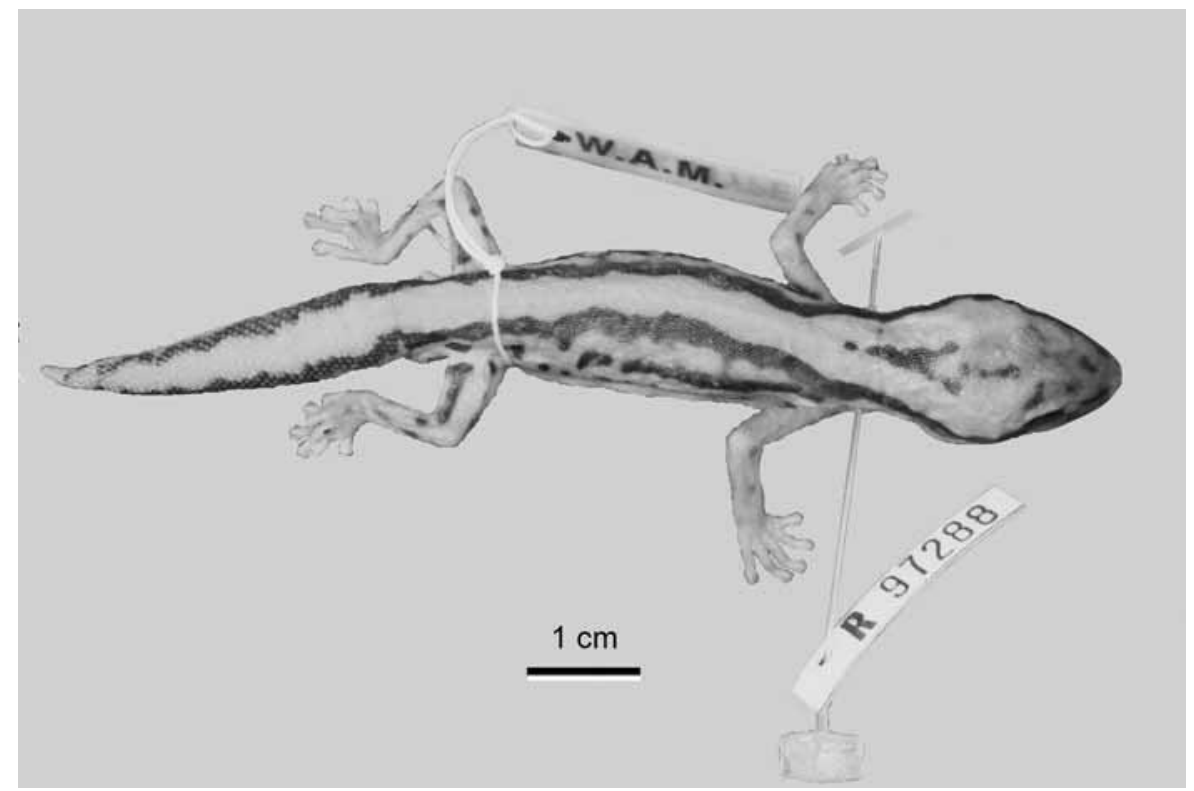

FIGURE 8. Holotype of Diplodactylus granariensis rex, WAM R97288.

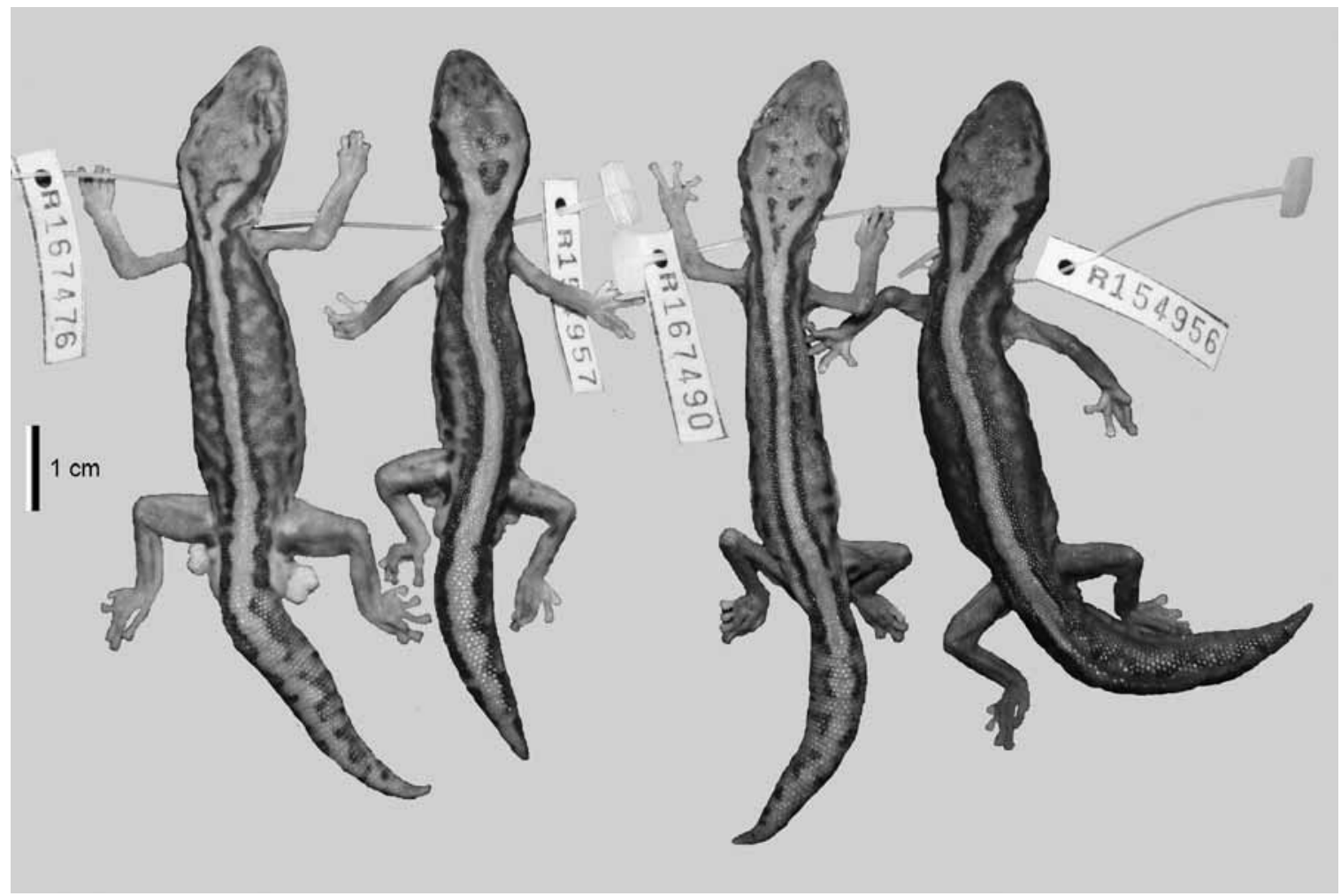

FIGURE 9. Variation in colour pattern in Diplodactylus granariensis rex

Description (Fig 8, 9, 12D). SVL 49.0-72.0 mm (mean 60.9, $\mathrm{n}=27$ ); tailL 24.0-42.0 mm, mean 34.5, (45.2-63.3 \% SVL, mean 59.8) $(\mathrm{n}=20)$. Supralabials 10-13 (mean 11.7, $\mathrm{n}=27)$, relative height of first and second supralabial generally subequal. Infralabials 10-13 (mean 11.3, n=27). Apex of rostral scale usually 
lacking a median division (small division evident in 4 of 27 examined). Supranasals usually in contact; a single internarial present in 3 of 27 examined. 1-4 postnasals (mean 3.1, $\mathrm{n}=27$ ).

Dorsal colour light to medium dark brown, greyish-brown or tan. Beige vertebral stripe continuous, with margins that vary from straight to scalloped. Vertebral stripe bifurcates on the nape to form two very wide stripes ending at the eyes. Inner margins of these stripes define a relatively small inverted triangle of the dorsal body colour confined to the parietal region. Blackish paravertebral margins of vertebral stripe strongly developed, tending to merge gradually with the colouring of the upper lateral zone, but sometimes forming a broad blackish dorsolateral stripe, well demarcated from both the vertebral and lateral colours. Upper lateral zone usually with a wavy dark stripe margined by paler colouring. At most, lateral patterning consists only of scattered small lighter spots that lack obvious dark margins.

Karyotype. Unknown.

Distribution. Arid interior of Western Australia, beyond the mulga-eucalypt line and south of the Gibson Desert, from the Ophthalmia Range near Newman, southeast to near Leonora and southwest to Paynes Find (Figs 1, 15).

Similar species. Distinguished from D. g. granariensis and all other Diplodactylus by presence of a dark lateral stripe, lack of a rostral crease and larger body size.

Remarks. Storr (1988) believed the two subspecies of $D$. granariensis to have allopatric distributions (see also Storr et al. 1990, p. 26), and this is still the case although the apparent gap has been narrowed by subsequent collections. Recent mtDNA and allozyme studies (Oliver et al. 2007a; Doughty et al. 2008) have shown that there are very few molecular differences between the two taxa, with $D$. g. granariensis being paraphyletic, the populations of $D$. g. rex forming a monophyletic crown group most closely related to northern populations of D. g. granariensis. Yet, D. g. rex is the most distinctive taxon morphologically within the species complex. We regard the status of rex as not yet firmly established, and so for this paper continue to recognize rex as a subspecies of D. granariensis. Continued use of subspecies helps to emphasise the very close genetic similarity between rex and geographically proximate populations of typical granariensis, in spite of obvious morphological differences. Detailed sampling in the region of overlap (running from about Mt Magnet to Leonora) would provide the specimens needed to establish whether there is gene flow between the taxa.

\section{Diplodactylus calcicolus sp. nov.}

South Coast Gecko

Figs. 10, 11, 14E

Diplodactylus 'southern', Oliver et al., 2007a

Holotype. SAMA R25343, adult male, from Hambidge Conservation Park, Eyre Peninsula, SA ( $33^{\circ} 26^{\prime} 40^{\prime \prime}$ S, $136^{\circ} 02^{\prime} 30^{\prime \prime}$ E), collected by the Mammal Club of the SA Field Naturalists' Society on 23 April 1984 (Fig. 8).

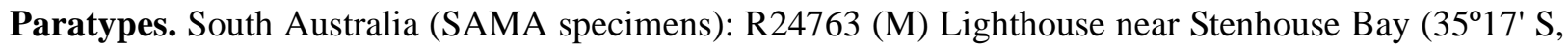
$136^{\circ}$ 57' E); R25382 (M) Ifould Campsite No. 2, $62 \mathrm{Km} \mathrm{N}$ Colona H/S (30 56' S, $132^{\circ}$ 05' E); R26257 (F) 10

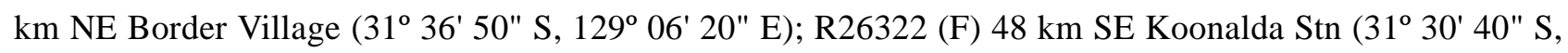
$130^{\circ} 21^{\prime} 30^{\prime \prime} \mathrm{E}$ ); R26495 (F) $11 \mathrm{~km}$ NE Border Village (31 35' 30" S, $129^{\circ} 07^{\prime}$ 20" E); R26496 (M), R26497

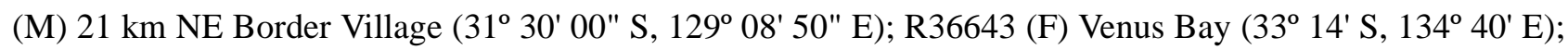

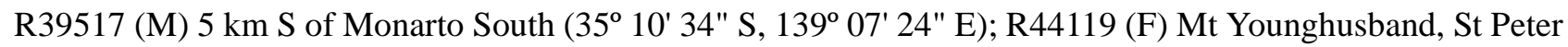

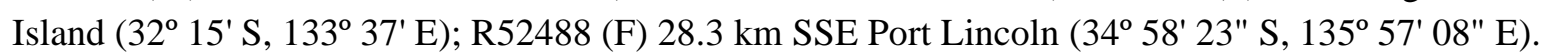

Western Australia (WAM specimens): R24602 (F) Eucla (31 43' S, 128 54' E); R39921 (M) 2 miles W Greenshield Soak (33 30' S, $118^{\circ} 49^{\prime}$ E); R56866 (F) Eyre (32 $15^{\circ}$ S, $126^{\circ} 18^{\prime}$ E); R91602 (M) 16 km E Toolinna Rockhole ( $32^{\circ} 40^{\prime} \mathrm{S}, 12^{\circ}$ 07' E); R91627, R91628 and R91630 (all M) 53km WNW Toolinna

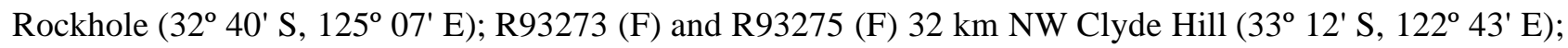




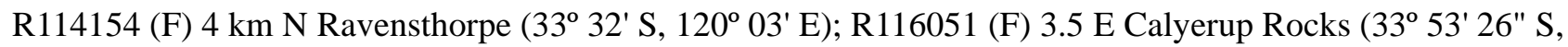

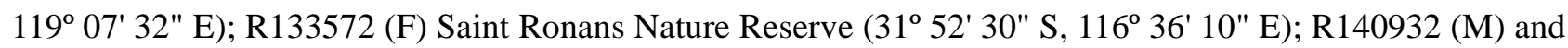
R140941 (M) 27.5 km SSE Peak Eleanora (33 10' S, $121^{\circ} 16^{\prime}$ E); R143815 (M) Lake Magenta Nature

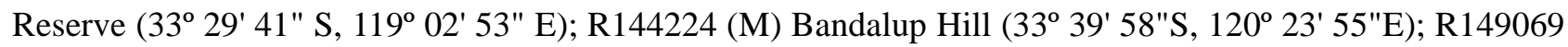

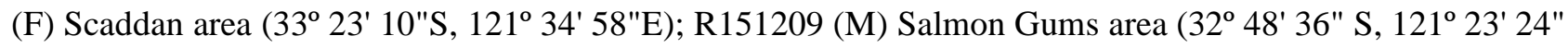

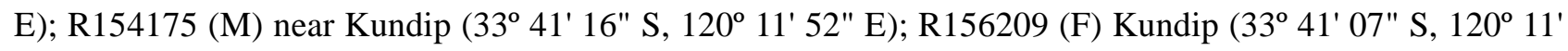
50" E); R156943 (M) and R156947 (M) Forrestania area (32 $\left.24^{\prime} \mathrm{S}, 119^{\circ} 41^{\prime} \mathrm{E}\right)$.

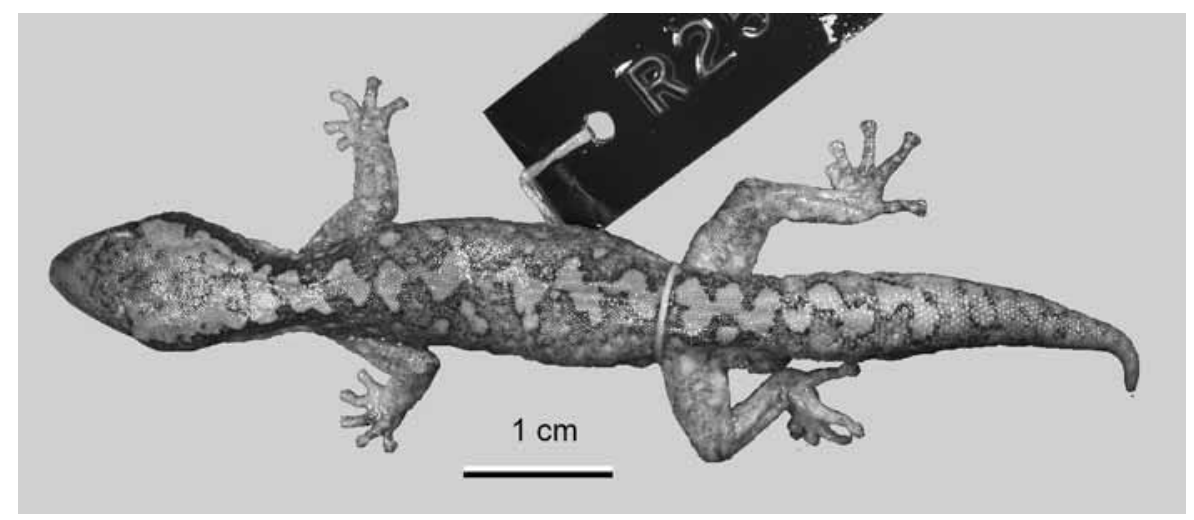

FIGURE 10. Holotype of Diplodactylus calcicolus sp. nov, SAMA R25343.

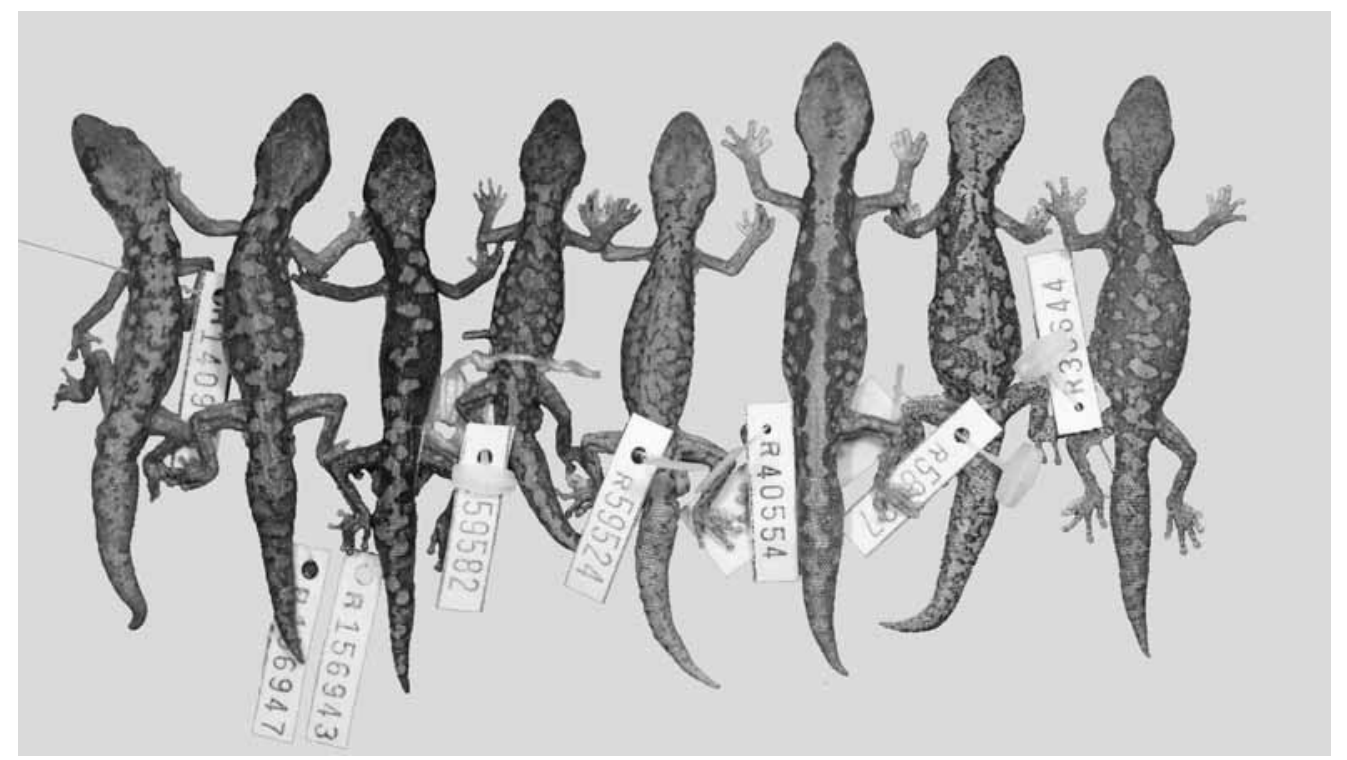

FIGURE 11. Variation in colour pattern in Diplodactylus calcicolus sp. nov. From left to right: western specimens (WAM R140935, WAM R156947, WAM R156943), Nullarbor specimens (SAM R59582, SAM R59524), and eastern specimens (SAM R40554, SAM R58537, SAM R36644).

Diagnosis. A moderate-sized, longer tailed member of the D. vittatus complex, typically with a highly broken and spotted pattern, but showing considerable within-population variation. Flanks marked with spots of various sizes, and background colour of dorsum usually variegated by a mixture of lighter and darker scales.

Description (Figs 10, 11, 14E). SVL 31.0-58.0 mm (mean 48.9, $\mathrm{n}=34$ ); tailL 24.5-38.0 mm, mean 32.4, (56.6-72.3\% SVL, mean 64.5) $(\mathrm{n}=18)$. Supralabials 10-13 (mean 11.5, $\mathrm{n}=17$ ), first and second supralabial generally subequal or the second slightly higher than the first. Infralabials 8-13 (mean 10.4, $n=17$ ). Apex of rostral scale with median division descending to about the mid-height of the scale. Supranasals usually in contact; a single internarial present in 5 of 34 examined. $2-5$ postnasals (mean 3.1, $\mathrm{n}=34$ ). 
The most variable in colour and pattern of the group. Dorsal colour pale to very dark brown, grey, or greybrown. Beige to pale grey vertebral stripe most often broken into a disconnected series of irregularly-shaped dorsal blotches, but within population variation can include individuals with a more continuous chain of blotches, or a continuous dorsal stripe with deeply to moderately scalloped margins. Vertebral stripe usually bifurcates on the nape with well-defined lateral margins but irregularly defined inner margins, so that the crown of the head tends to be paler laterally but with a darker, weakly defined central patch of background colour. Blackish paravertebral margins of vertebral stripe variable in contrast, but even if prominent, often discontinuous due to random interruptions by lighter scales. Upper lateral zone sometimes patterned with irregularly distributed circular spots; some specimens with very large spots, similar in size to the vertebral series of blotches. Apart from such spots, the upper lateral surfaces have a 'messy' texturing of lighter and darker scales overlying the medium-toned background colour. Ventral surface white to greyish white.

Karyotype. $2 n=38$ (King 1977).

Distribution. Distributed along the dry temperate to arid southern coast and hinterland of Australia, from near Perth, WA, south to Albany (absent from southwest corner) and along the Great Australian Bight to the Eyre Peninsula, with outliers on the southern York Peninsula and the mouth of the Murray River (Figs 1, 15, 16) .

Etymology. The specific name has been constructed from Latin roots 'calci' (lime) and 'cola' (inhabitant), referring to the dominant limestone geology of the coast and hinterland of the Great Australian Bight, the central area of the species' distribution.

Similar Species. This is the most variable species within the complex, and it overlaps geographically with all other taxa treated here except $D$. g. rex. Within most populations of D. calcicolus a minority of specimens have a continuous vertebral stripe combined with weakly marked flanks. Such individuals are difficult to distinguish from sympatric individuals of D. furcosus, D. g. granariensis, or D. vittatus. The stripe is more irregular than in either of the other species, the flanks have intermixed darker and lighter scales rather than being uniformly coloured and the occipital markings are usually more poorly defined (Fig. 9). The longer tail of D. calcicolus sp. nov. further distinguishes it from D. vittatus in the small overlap zone on the lower Murray River. In the southwest of Western Australia, the diffuse spotted markings of D. polyophthalmus are unlike the more solidly delineated and irrregular spots of $D$. calcicolus. At present, distinguishing some far western $D$. calcicolus sp. nov. from geographically proximate individuals of $D$. ornatus can be difficult. More detailed genetic comparisons among Perth area Diplodactylus populations, focusing on the distinctions between $D$. calcicolus $\mathbf{s p}$. nov. and D. ornatus, will be necessary before the unambiguous genetic distinction can be matched by equally clear morphological characters. .

Remarks. This species mostly occurs in cool dry habitats, typically on limestone or calcareous coastal sands. Oliver et al. (2007a) noted that this species comprises three genetic lineages that do not correspond to any obvious patterns of variation in the characters discussed above.

\section{Diplodactylus wiru sp. nov.}

Desert Wood Gecko

Figs. 12, 13, 14F

Diplodactylus 'GVD' Oliver et al., 2007a

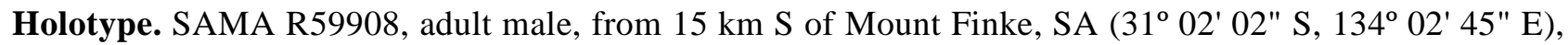
collected by D. Armstrong on 27 November 2004 (Fig. 10).

Paratypes. South Australia (SAMA specimens): R18202 (F) SW Wyola Lake (29 $30^{\prime}$ S, $130^{\circ} 10^{\prime}$ E); R31848 (F) 17 km ESE Mt Christie Siding (30 37' 37" S, 13317' 04" E); R31863 (M) 15 km SSE Mt Christie

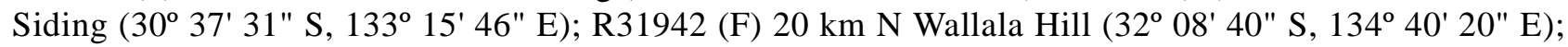
R31946 (M), R31947 (M), R31951 (M) S Inila Rock Waters Yumbarra Conservation Park (31 48' 14" S, $133^{\circ}$ 24' 05" E); R31963 (F) 1.5 km S Inila Rock Waters Yumbarra Conservation Park (31 $47^{\circ} 42^{\prime \prime}$ S, $133^{\circ} 25^{\prime} 44^{\prime \prime}$ E), R32052 (M) 5.5 km S Immarna Siding (30 33' 07" S, 132º 08' 42" E); R32097 (F) 9.5 km WNW Immarna 
Siding (30 29' 16" S, 132 03' 35" E); R45552 (M) 6 km NNE of Inila Rock Waters Yumbarra Conservation

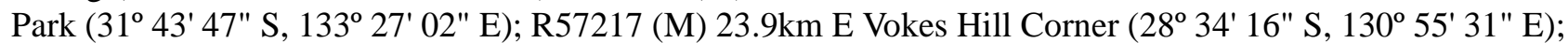

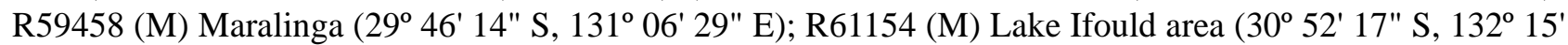

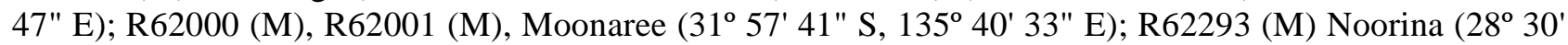
30" S, $129^{\circ} 12^{\prime} 37^{\prime \prime}$ E); R62367 (M) Vokes Hill (28 32' 25" S, 13002' 49" E); R62465 (F) Childara rockhole ( $\left.31^{\circ} 36^{\prime} 18^{\prime \prime} \mathrm{S}, 134^{\circ} 26^{\prime} 48^{\prime \prime} \mathrm{E}\right)$.

Western Australia (WAM specimens): R100622, R135291 (M) $25 \mathrm{~km}$ NNE Queen Victoria Spring (30 ${ }^{\circ}$ 14' S, $\left.123^{\circ} 43^{\prime} \mathrm{E}\right)$; R157876 (30 $\left.14^{\prime} \mathrm{S}, 123^{\circ} 43^{\prime} \mathrm{E}\right)$.

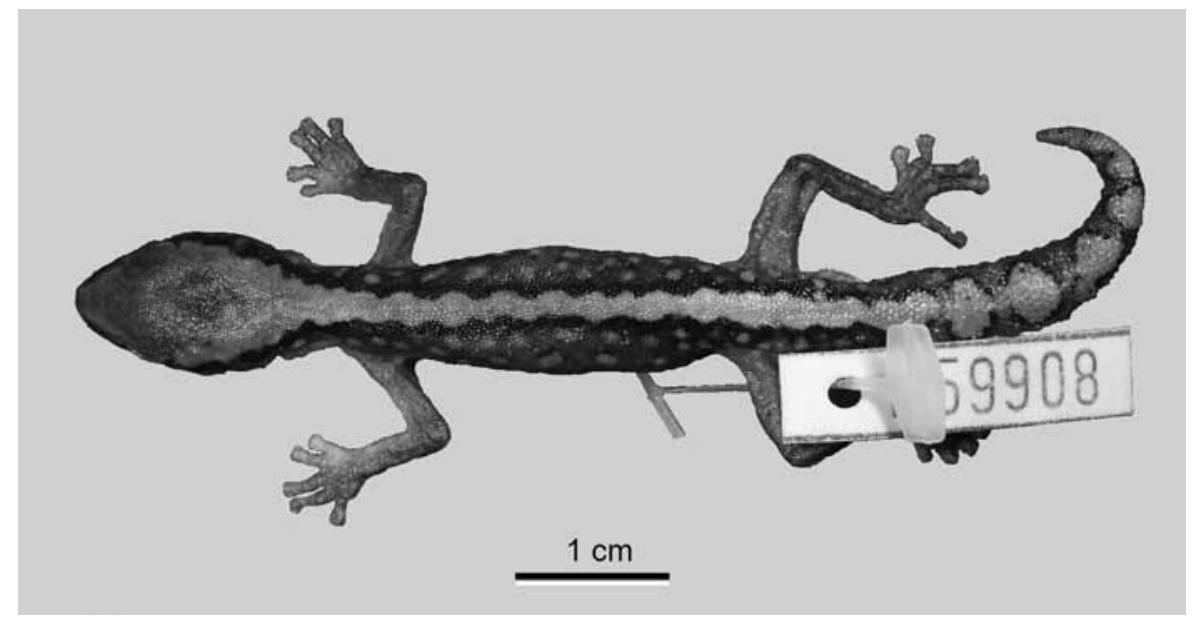

FIGURE 12. Holotype of Diplodactylus wiru sp. nov, SAMA R59908..

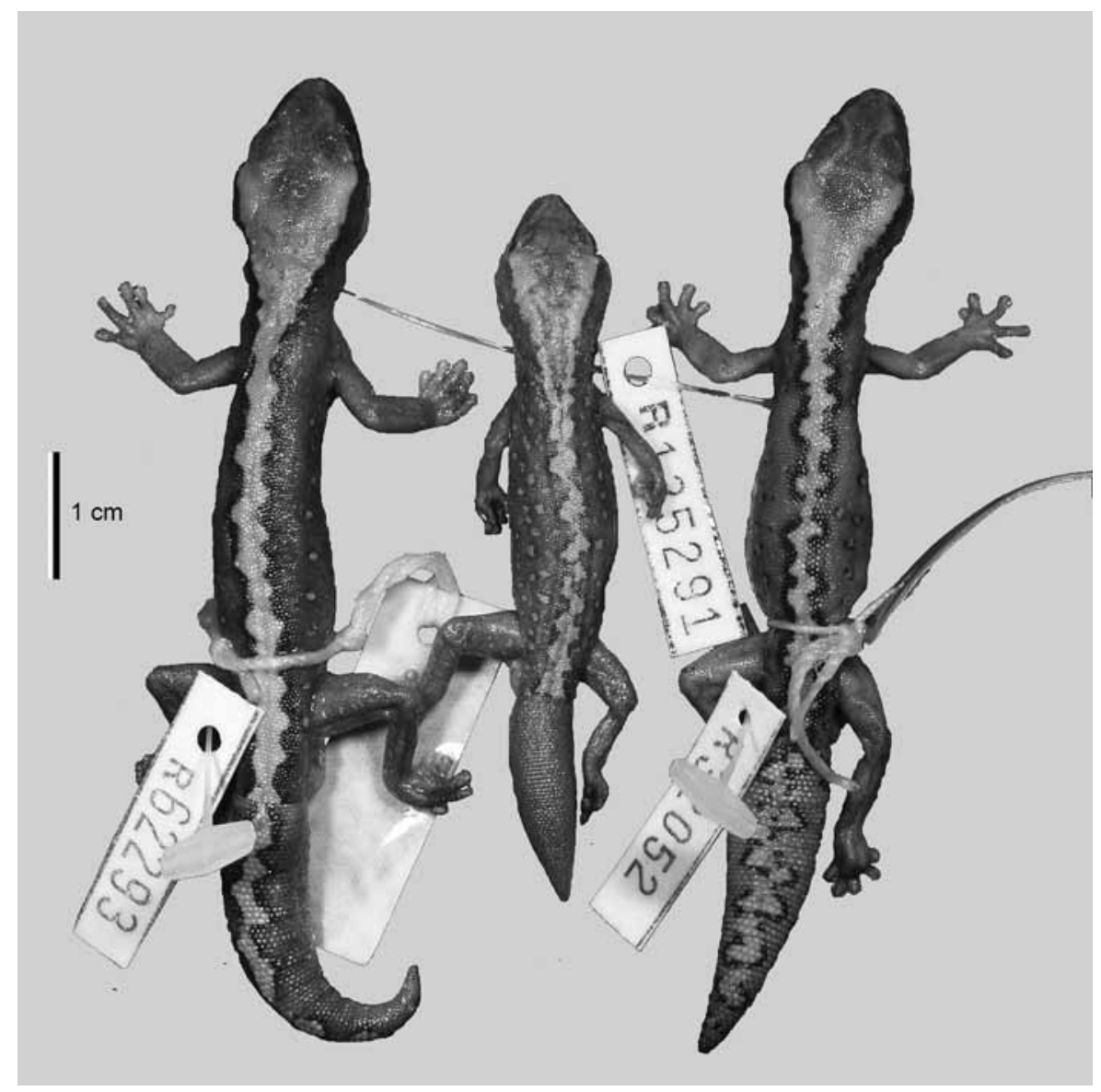

FIGURE 13. Variation in colour pattern in Diplodactylus wiru sp. nov. Middle specimen is a juvenile. 

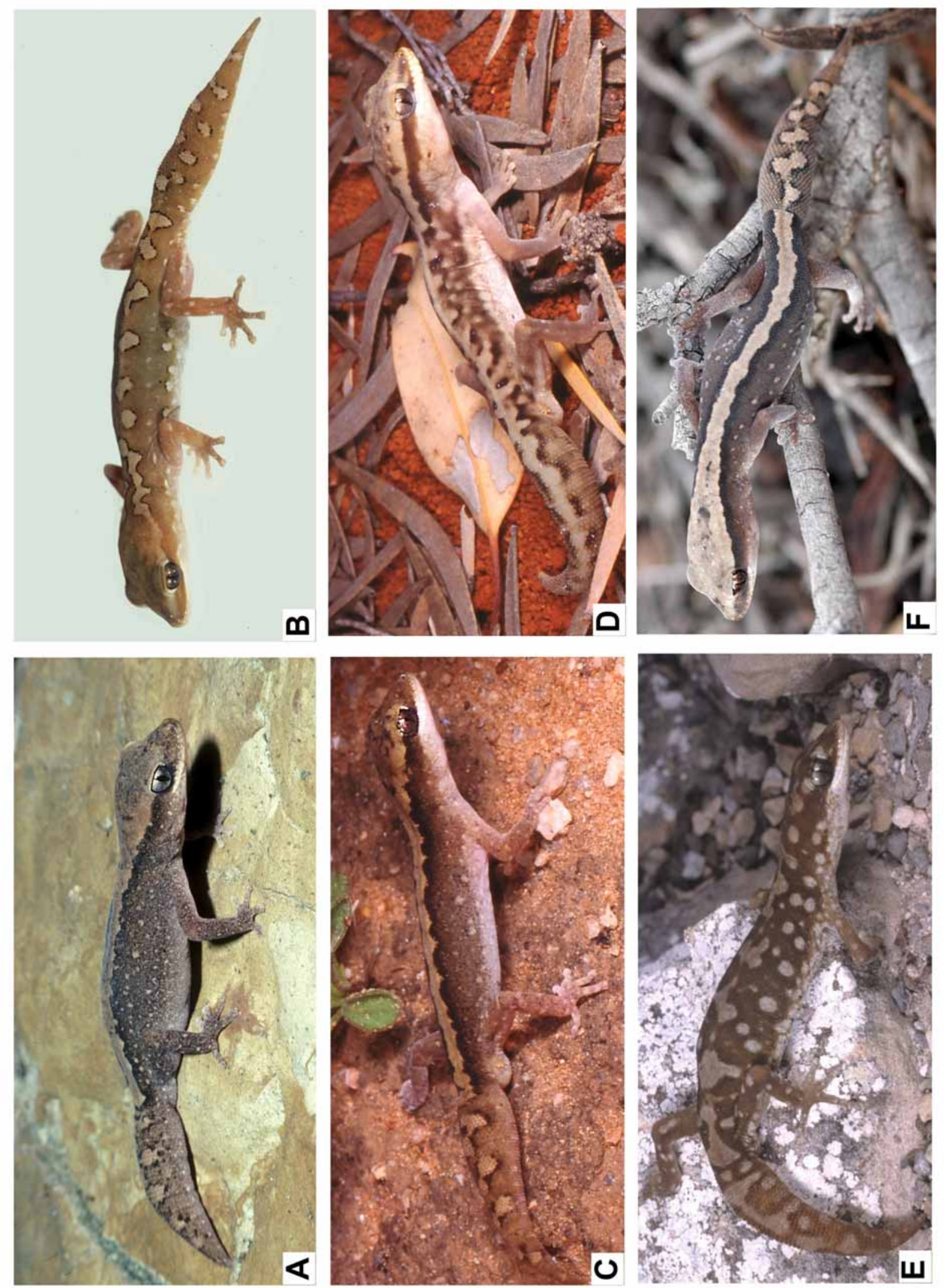

FIGURE 14. Species of the Diplodactylus vittatus complex in life. A, D. vittatus, Warrumbungle Range, NSW, (M. Hutchinson); B, D. furcosus, Whyalla, South Australia (T. Peters, SA Museum); C, D. g. granariensis, Newman Rock, WA (B. Maryan); D, D. g. rex, Wildara Pinnacle, WA (B. Maryan); E, D. calcicolus sp. nov., vicinity of the WA-SA border (G. Harold); F, D. wiru sp. nov. Lake Ifould, SA (P. Oliver). 
Diagnosis. A moderate-sized member of the D. vittatus complex, showing relatively little variation compared with other members of the complex. Well-developed, almost straight-edged to zigzag dorsal stripe always present, broadly bordered by black; light dorsal colour extends on to occiput as a pale cap with somewhat darker centre, but no well-defined bifurcate pattern; flanks dark grey with one or more rows of well-defined, dark-edged circular spots.

Description (Figs 12, 13, 14F). SVL 41.0-59.5 mm (mean 54.0, $\mathrm{n}=23$ ); tailL 32.0-39.0 mm, mean 35.5 (56.1-67.3\% SVL, mean 61.9) ( $\mathrm{n}=11)$. Supralabials 11-14 (mean 11.9, $\mathrm{n}=11$ ), first supralabial generally higher than the second. Infralabials 10-14 (mean 11.3, $\mathrm{n}=11$ ). Apex of rostral scale with median division descending to about the mid-height of the scale (absent in one specimen). Supranasals in contact (13/23), separated by a single internarial (8/23) or separated by two internarials (2/23). 2-4 postnasals (mean 3.2, $\mathrm{n}=23)$.

Dorsal colour medium to dark brownish grey. Beige vertebral stripe almost always continuous, but with strongly scalloped margins; less scalloped to almost straight-edged in a minority of specimens. Vertebral stripe expands to a pale cap on the head, colour uniform or with at most a weakly evident darker parietal patch. Blackish paravertebral margins of vertebral stripe strongly developed, tending to merge laterally with the colouring of the upper lateral zone. Upper lateral zone usually well marked with a series of relatively large dark-edged, circular spots (the dorsal edge is often heavier marked than the ventral edge of the spots) and sometimes with a dorsolateral series of smaller spots. Apart from the prominent spots, the upper background colour of the upper lateral zone is uniform, without a peppering of lighter or darker scales. Ventral surface offwhite.

Karyotype. $2 \mathrm{n}=38$, all acrocentric (King 1977).

Distribution. Southern Great Victoria Desert and adjacent sandy habitat blocks. Records extend southwest to Norseman, WA, and east to the Lake Acraman area, Gawler Ranges, SA (Figs 1, 15, 16). Northern limits appear to be at about the level of the Serpentine Lakes, SA. Absent from the Nullarbor Plain. The absence of $D$. wiru sp. nov. from the area immediately west of the WA border likely represents a gap in collecting effort.

Etymology. The specific epithet is an adjective from the western desert languages (e.g. Pitjantjatjara, Ngaatjatjarra), wiru meaning 'beautiful' or 'fine' (Goddard 1996); chosen to highlight the bold markings of this species.

Similar Species. Distinguished from sympatric and parapatric species as follows: from D. granariensis by the presence of a well-defined dark-edged light lateral spots arranged in one or more longitudinal series and absence of a bifurcate pattern on the occiput, and the first supralabial consistently taller than the second; from $D$. furcosus by the pale occipital cap rather than a bifurcate occipital marking and the blackish outlines to the light dorsal markings thick and often merging into the dorsal background colour, rather than narrow and sharply distinct from the dorsal background colour; from D. calcicolus $\mathbf{s p . ~ n o v . ~ b y ~ t h e ~ c o n t i n u o u s , ~ r e g u l a r l y ~}$ arranged dorsal stripe and lateral series of spots rather than large irregular blotches, and unicoloured rather than minutely variegated background colour of the flanks.

Remarks. Specimens pit-trapped or observed at night have been associated with large mallee eucalypts with extensive ground litter of fallen bark, branches and leaves. Unlike syntopic species of Lucasium ( $L$. damaeum Lucas and Frost, 1896 and L. bungabinna Doughty and Hutchinson, 2008) which were generally found in open sandy patches, specimens of $D$. wiru sp. nov. appeared to stay close to woody debris and 'cluttered' understorey cover (MNH, PMO, pers. obs.). The distributional pattern of $D$. wiru sp. nov. is highly congruent with those of a number of species that occur in a narrow band of sandy mallee vegetation communities that lie between the semiarid south coast and hinterland and the Great Victoria Desert (Doughty \& Hutchinson 2008). 


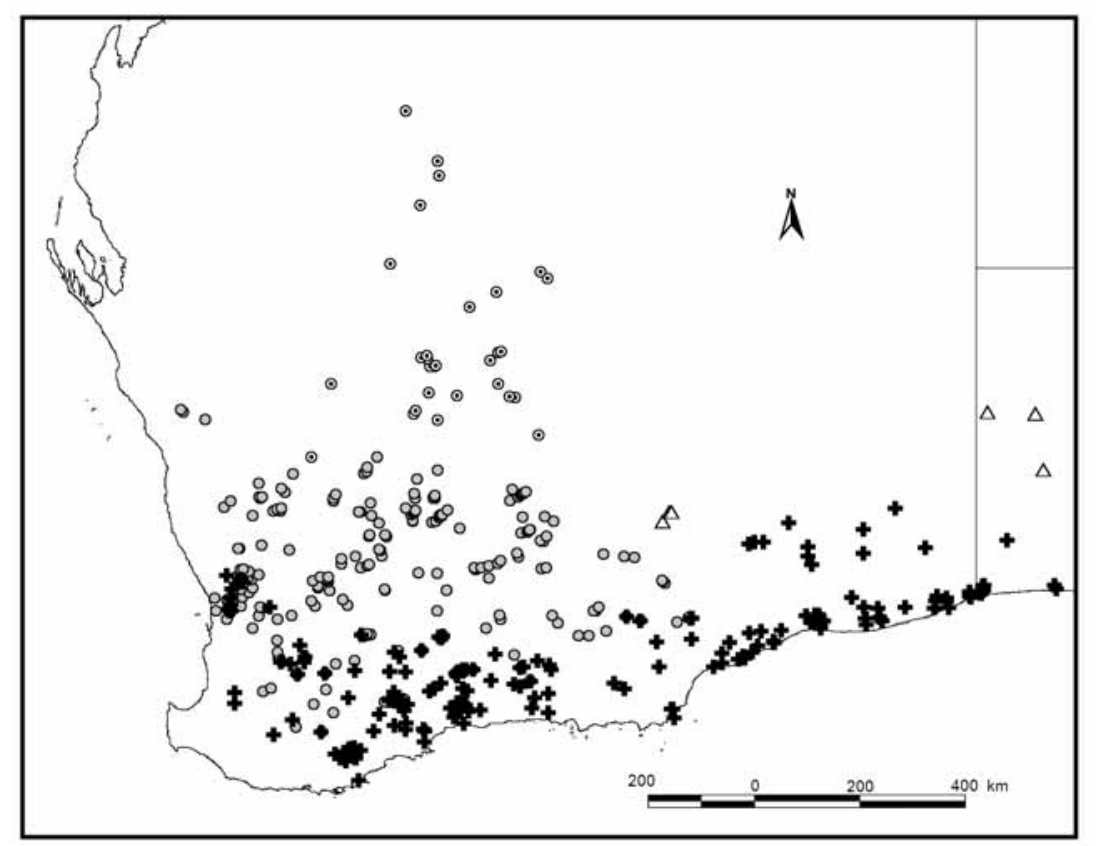

FIGURE 15. Detail of distribution of $D$. vittatus complex in Western Australia. Note significant range overlap of $D$. granariensis and D. calcicolus sp. nov. in the southwest. Symbols as in Fig. 1.

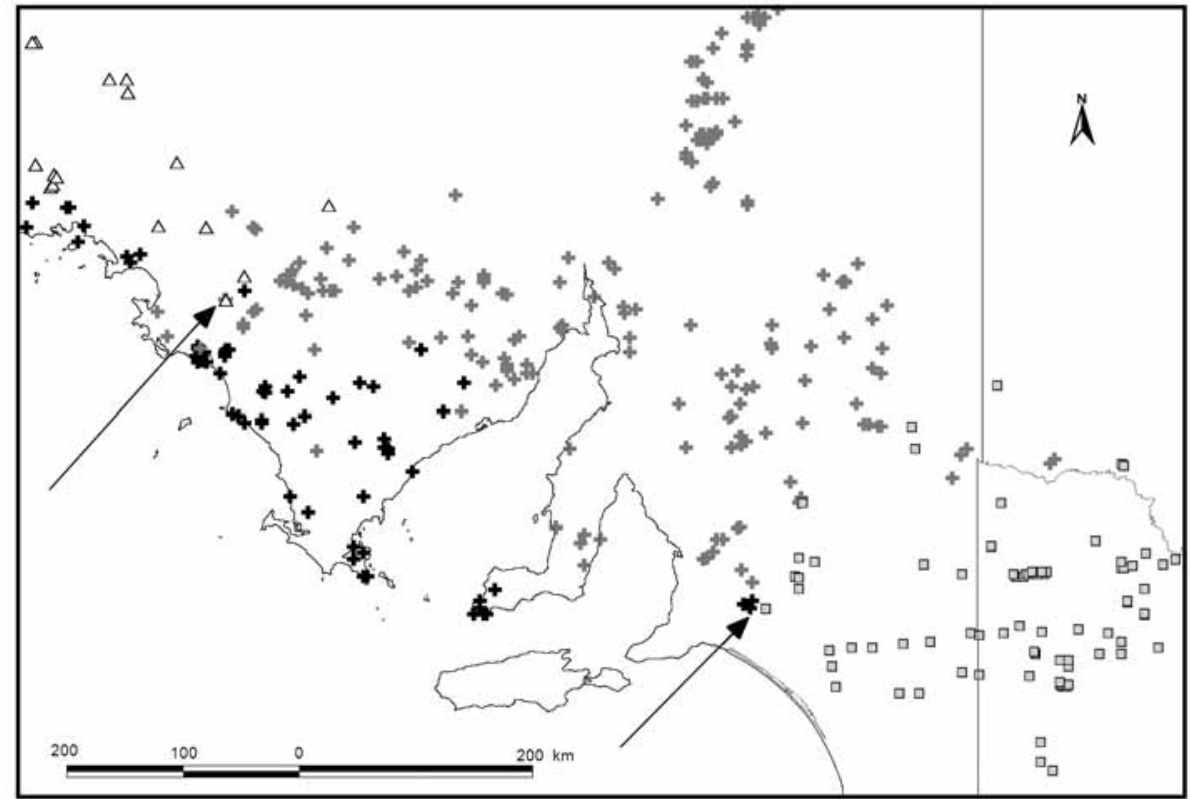

FIGURE 16. Detail of distribution of $D$. vittatus complex in South Australia. Note significant range overlap of $D$. furcosus and D. calcicolus sp. nov. on Eyre Peninsula, and the two regions (arrowed) where three species are sympatric. Symbols as in Fig. 1.

\section{Discussion}

After a delay of over 30 years, the last of Max King's suspicions regarding the presence of cryptic species within Kluge's Diplodactylus vittatus have been verified and exceeded. The crucial development has been the application of molecular genetic approaches for analyzing gene flow and species boundaries. Within what was regarded a single wide-ranging and variable species (Kluge 1967), there are now eight recognized taxa: $D$. vittatus, D. furcosus, D. ornatus, D. polyophthalmus, D. g. granariensis, D. g. rex, D. calcicolus $\mathbf{s p .}$ nov. and 
D. wiru sp. nov. Even this understates the likely final tally as there are problematic populations within this complex that suggest further species may eventually be recognized (see below).

While each species has a modal colour scheme that is distinctive, there is sufficient variation within species to cause potential confusion. The problem is simplified when distributions are examined in detail (figs 15, 16). The strongly allopatric distributions commented on by Oliver et al. (2007a) are not as exclusive as initially thought, but it is clear that, in any given geographic region, most species overlap with no more than one other member of the complex. We know of only two areas where three species in the complex occur sympatrically. The first is the region south of the Gawler Ranges, SA, centred near the town of Minnipa ( $D$. calcicolus sp. nov., D. furcosus, D. wiru sp. nov.), and the second is the lower Murray River Valley in the vicinity of Murray Bridge (D. vittatus, D. furcosus and D. calcicolus sp. nov.). Throughout the range of the complex, therefore, it is fairly straightforward to make the pairwise comparison necessary for identification. However, no-data or poorly localized specimens may be difficult, and in some cases it may be necessary to resort to genetic methods to confirm identification.

A feature of the variation exhibited within the complex is that species differ in the degree of morphological variation that they display. For example, $D$. wiru sp. nov. showed little intraspecific variation and all individuals conformed to a single colour pattern. In contrast, D. calcicolus sp. nov. showed an unusually large amount of colour pattern variation that overlapped with several other species. The confusion caused by the presence of both narrowly varying and widely varying species would have contributed to earlier difficulties in discerning intra- versus interspecific variation, such as Storr's (1979) composite description of D. granariensis. Other examples in Australian herpetology, such as Pseudemoia (Hutchinson \& Donnellan 1992), the Ctenotus brooksi complex (Hutchinson et al. 2006) and Mixophyes (Mahony et al. 2006) show that a widespread and widely varying member of a species complex often conceals the presence of more narrowly varying siblings.

While this work is significant step towards stabilizing the taxonomy of the vittatus group there are two obvious priorities for additional study. In the Perth area and adjacent southwest of Western Australia the distributions of D. granariensis, D. calcicolus sp. nov. and D. ornatus abut or overlap. The morphological features that can reliably distinguish the three species in this area will need further refinement once more individuals from this region have been genetically typed. The second and largest remaining issue in the group is the status of $D$. vittatus itself. There are two well-differentiated mitochondrial sister clades within this species as we conceive it. We have identified at least one instance of near sympatry of these two clades with no allozyme evidence of interbreeding in the Warrumbungles area of northern New South Wales (Oliver et al. 2007a). However at present genetic sampling is too incomplete to understand the considerable morphological variation within nominal D. vittatus, especially in the portion of its range north of Sydney, NSW and into Queensland. Given the overlapping patterns of morphological variation shown by other members of this species group, and the vast range of $D$. vittatus, the possibility that additional deeply divergent, but morphologically cryptic taxa await recognition cannot be discounted. Extensive future collecting of tissue and specimens will be required to establish both the number and distribution of taxa currently included within $D$. vittatus.

\section{Acknowledgments}

We thank Patrick Couper and Andrew Amey, Queensland Museum, Ross Sadlier, Australian Museum, and Jane Melville and Di Bray, Museum Victoria, Rainer Günther Alexander Humboldt Museum, Berlin, for specimens and distributional data; Hal Cogger for photographs of the types of D. vittatus and D. furcosus; Greg Harold, Brad Maryan and Trevor Peters for live photographs. Comments from Glenn Shea, Paul Horner and Aaron Bauer greatly improved the manuscript. This work was funded by grants from the Sir Mark Mitchell Foundation, Australian Biological Resources Survey and the Australia Pacific Science Foundation. 


\section{References}

Bauer, A.M., \& Henle, K. (1994) Das Tierreich 109, Familia Gekkonidae (Reptilia: Sauria). Part I. Australia and Oceania. Walter De Gruyter Publishers, Berlin, 306 pp.

Brygoo, E.R. 1991. Les types de gekkonidés (Reptiles, Sauriens) du Muséum national d'Histoire naturelle. Catalogue critique. Bulletin du Muséum National d'Histoire Naturelle., Paris (4)12, 19-141.

Cogger, H.G. (1983) Reptiles and Amphibians of Australia ( $3^{\text {rd }}$ edition). Reed Books, Sydney, NSW, Australia, 660 pp.

Cogger, H.G., Cameron, E.E. \& Cogger, H.M. (1983) Zoological Catalogue of Australia. Vol 1. Amphibia and Reptilia. Bureau of Fauna and Flora, Canberra, vi+313 pp..

Doughty, P. \& Hutchinson, M.N. (2008) A new species of Lucasium (Squamata: Diplodactylidae) from the southern deserts of Western Australia and South Australia. Records of the Western Australian Museum, 25, 95-106.

Doughty, P., Oliver, P. \& Adams, M. (2008) Systematics of stone geckos in the genus Diplodactylus (Reptilia: Diplodactylidae) from northwestern Australia, with a description of a new species from the Northwest Cape, Western Australia. Records of the Western Australian Museum, 24, 247-265.

Gamble, T., Bauer, A.M., Greenbaum, E. \& Jackman, T.R. (2008) Evidence for Gondwanan vicariance in an ancient clade of gecko lizards. Journal of Biogeography, 35, 88-104.

Goddard, C. (1996) Pitjantjara / Yunkunytjatjara to English Dictionary. IAD Press, Alice Springs, xiv+306 pp.

Gray, J.E. (1832) Three new animals brought from New Holland by Mr Cunningham. Proceedings of the Zoological Society of London, 1832, 39-40.

Gray, J.E. (1845) Catalogue of the Specimens of Lizards in the Collection of the British Museum. British Museum, London, UK, xxviii+289 pp.

Günther, A. (1867) Additions to the knowledge of Australian reptiles and fishes. Annals and Magazine of Natural History (3), 20, 45-68.

Han, D., Zhou, K. \& Bauer, A.M. (2004) Phylogenetic relationships among gekkotan lizards inferred from $C$-mos nuclear DNA sequences and a new classification of the Gekkota. Biological Journal of the Linnean Society, 83, 353-368.

Hutchinson, M.N. \& Donnellan, S.C. (1992) Taxonomy and genetic variation in the Australian lizards of the genus Pseudemoia (Scincidae: Lygosominae). Journal of Natural History, 26, 215-264.

Hutchinson, M.N., Adams, M. \& Fricker, S. (2006) Genetic variation and taxonomy of the Ctenotus brooksi speciescomplex (Squamata: Scincidae). Transactions of the Royal Society of South Australia, 130, 48-65.

King, M. (1977) Chromosomal and morphometric variation in the gecko Diplodactylus vittatus (Gray). Australian Journal of Zoology, 25, 42-57.

Kluge, A.G. (1967) Systematics, phylogeny and zoogeography of the lizard genus Diplodactylus Gray (Gekkonidae). Australian Journal of Zoology, 15, 1007-1108.

Lucas, A.H.S. \& Frost, C. (1896) Reptilia. In: Spencer, W.B. (Ed.), Report on the Work of the Horn Scientific Expedition to Central Australia, Part. II. - Zoology. Melville, Mullen \& Slade, Melbourne, Victoria, Australia, pp. 112-151.

Mahony, M., Donnellan, S.C., Richards, S.J. \& McDonald, K.R. (2006) Species boundaries among barred river frogs, Mixophyes (Anura : Myobatrachidae) in north-eastern Australia, with descriptions of two new species. Zootaxa, 1228, 35-60.

McMinn, W.G. (1970) Alan Cunningham. Botanist and Explorer. Melbourne University Press, Melbourne, ix +147.

Oliver, P., Hugall, A., Adams, M., Cooper, S.J.B. \& Hutchinson, M. (2007a) Genetic elucidation of ancient and cryptic diversity in a group of Australian geckos: the Diplodactylus vittatus complex. Molecular Phylogenetics and Evolution, 44, 77-88.

Oliver, P.M., Hutchinson, M.N. \& Cooper, S.J.B. (2007b) Phylogenetic relationships in the lizard genus Diplodactylus Gray and resurrection of Lucasium Wermuth (Gekkota, Diplodactylidae). Australian Journal of Zoology, 55, 197-210.

Oliver, P.M., Adams, M., Lee, M.S.Y., Hutchinson, M.N. \& Doughty, P. (2009) Cryptic diversity in vertebrates: molecular data double estimates of species diversity in a radiation of Australian lizards (Diplodactylus, Gekkota). Proceedings of the Royal Society B, 276, 2001-2007.

Peters, W. (1863) Eine Übersicht der von Hrn. Richard Schomburgk an das zoologische Museum eingesandten Amphibien, aus Buchsfelde bei Adelaide in Südaustralien. Monatsberichte der K. Preussisches Akademie von Wissenschaft, Berlin, 1863, 228-236.

Storr, G.M. (1979) The Diplodactylus vittatus complex (Lacertilia: Gekkonidae) in Western Australia. Records of the Western Australian Museum, 7, 391-402.

Storr, G.M. (1988) Three new Diplodactylus (Lacertilia: Gekkonidae) from the arid zone of Australia. Records of the Western Australian Museum, 14, 217-223.

Storr, G.M., Smith, L.A. \& Johnstone, R.E. (1990) Lizards of Western Australia. III. Geckos and Pygopods. Western Australian Museum Press, Perth, WA, Australia. $\mathrm{x}+141 \mathrm{pp}$. 
Underwood, G. (1954) On the classification and evolution of geckos. Proceedings of the Zoological Society of London 124, 469-492.

Wilson, S.K. \& Swan, G. (2008) A Complete Field Guide to Reptiles of Australia, second edition. Reed New Holland, Sydney, NSW, Australia, 512 pp.

\section{APPENDIX. Specimens scored for in the morphological characters, R-, D (NMV) or J- (QM) prefixes excluded.}

Diplodactylus vittatus

SAMA: 15670, 33366, 33735, 34745, 34746, 34764, 34765, 34766, 39397, 39400, 39412, 39439, 39483, 39539, 39586, 39592, 39624, 42470, 45213, 46660, 53011, 53012, 141100, 152148, 156719, 158588, 159535.

AMS: $141100,152148,156719,158588,159535$.

QM: 59785, 78206, 79982, 79989.

NMV: $71906,71907$.

Diplodactylus furcosus

SAMA: 19247, 19887, 28400, 28440, 36618, 36649, 40195, 41131, 41758, 46263, 49155, 50243, 52004, 52116, 52376, 52508, 52899, 53014, 53015, 53093, 53302, 53525, 54076, 55204, 58066, 58067, 58161, 59202.

AMS: $156751,156755$.

Diplodactylus g. granariensis

WAM: 72278, 72361, 72602, 72718, 74347, 74518, 76042, 81328, 81342, 84452, 93462, 96573, 103846, 103857, $110779,127572,132023,132278,134044,134106,134816,135210,136581,137776,144170,144551,144551$, $144780,151675,153946,153947,153948,153949,153950,161181$.

Diplodactylus g. rex

WAM: 97289, 100350, 112102, 113191, 132504, 136593, 136619, 136802, 140415, 141120, 141121, 141122, 144718, $145285,145448,151421,154934,154944,154955,154956,154957,161164,167476,167485,167490$.

Diplodactylus calcicolus sp. nov.

SAMA: 24763, 25343, 25382, 26257, 26322, 26495, 26496, 26497, 36643, 39517, 44119, 52488.

WAM: 24602, 39921, 56866, 91602, 91627, 91628, 91630, 93273, 93275, 114154, 116051, 133572, 140932, 140941, $143815,144224,149069,151209,154175,156209,156943,156947$.

Diplodactylus wiru sp. nov.

SAMA: 15664, 18202, 31848, 31863, 31942, 31946, 31947, 31951, 31963, 32052, 32097, 32303, 45552, 57217, 59458, $59908,61154,62001,62293,62367,62465,62900$.

WAM: 135291. 